\title{
The dark side of a tumor suppressor: anti-apoptotic p53
}

\author{
RU Jänicke ${ }^{*, 1}$, D Sohn ${ }^{1}$ and K Schulze-Osthoff ${ }^{1}$
}

Depending on multiple factors DNA damage leads either to cell cycle arrest or apoptosis. One of the main players deciding the fate of a cell is the tumor suppressor p53 that modulates these responses in a transcription-dependent and -independent manner. Over the past few years, however, strong evidence accumulated that p53 engages also powerful pro-survival pathways by transcriptionally activating a multitude of genes whose products efficiently counteract apoptosis. Our review summarizes the current knowledge concerning approximately forty p53-regulated proteins that exert their anti-apoptotic potential by interfering with diverse cellular processes. These activities are surely essential for normal development and maintenance of a healthy organism, but may easily turn into the dark side of the tumor suppressor p53 contributing to tumorigenesis.

Cell Death and Differentiation (2008) 15, 959-976; doi:10.1038/cdd.2008.33; published online 21 March 2008

Throughout their life cycle, organisms constantly face a more or less severe damage to their DNA that can be caused by endogenous stress during normal respiration and replication or by exogenous sources such as ultraviolet (UV) and ionizing irradiation (IR). Depending on multiple factors including source and extent of an insult, DNA damage leads either to cell cycle arrest in which the cell is given the opportunity to repair damaged DNA or to the complete disposal of the cell by a process called apoptosis. Although the mechanisms responsible for this decision are far from being elucidated, they are not mutually exclusive and orchestrated by components that are critical for both processes. One of the main players deciding the fate of a cell following DNA damage is the tumor suppressor p53 that can modulate these events in a transcription-dependent and -independent manner. ${ }^{1,2}$

Under normal conditions, p53 is a short-lived protein that is constantly subjected to degradation by the proteasome. Upon stress exposure p53 is rapidly phosphorylated and otherwise post-translationally modified leading to its stabilization and activation. ${ }^{3}$ These modifications also increase the ability of p53 to bind to specific DNA promoter sequences leading to an enhanced transcription of p53-regulated genes. Among many others, those include genes that contribute to DNA repair, cell cycle arrest and apoptosis. ${ }^{4,5}$ In addition, p53 was postulated to modulate these events, at least partially, via transcriptionindependent mechanisms that might involve direct binding to anti-apoptotic Bcl-2 proteins at the mitochondria. ${ }^{2,6}$ However, this model has been seriously challenged as both $\mathrm{Bcl}-\mathrm{X}_{\mathrm{L}}$ and $\mathrm{Bcl}-2$ were shown to bind $\mathrm{p} 53$ with a significantly weaker affinity ( $>100$ and $>500 \mathrm{nM}$, respectively) than they bind the proapoptotic BH3-only protein Puma $(<1 \mathrm{nM}){ }^{7,8}$ Together with the observation that p53 was also found to translocate to mitochondria in the absence of apoptosis induction, ${ }^{9}$ these reports cast a general doubt on this model. Nevertheless, the multiple transcription-dependent activities ward p53 a tremendous potential as a tumor suppressor protein as they are surely not only essential for the maintenance of the genomic integrity of an organism thereby preventing tumorigenesis, but also for eradication of established tumors that may have developed from cells with unrepaired DNA lesions. Thus, one sure road to tumor development entails removal of p53, a mechanism that is indeed observed in $50 \%$ of all human cancers.

Especially the pro-apoptotic activities of p53 are well documented and highly appreciated as one important facet of its multiple tumor suppressor functions. However, over the past few years it became clear that there exists a second, relatively unforeseen and unexplored facet to this story implicating p53 also as an active mediator of pro-survival signaling pathways. ${ }^{10}$ In fact, in addition to the death squad enlisted by the tumor suppressor $p 53,{ }^{5}$ a multitude of $p 53$ targets with opposing functions have surfaced implying an even more complex p53 signaling network than previously anticipated (Table 1). To our knowledge, this other antiapoptotic side of p53 was only reviewed very rarely in the past prompting us to summarize findings on this subject in an adequate, yet compact manner. As p53 affects and is affected by a multitude of different signaling pathways that are all sensed, controlled and mediated by a complex network of numerous components, it is surely beyond the scope of this review and therefore not our intention to provide the reader with a detailed description of each of these pathways, but we rather would like to focus on a few anti-apoptotic mechanisms that have been clearly demonstrated to be mediated by the most versatile $\mathrm{p} 53$ protein.

${ }^{1}$ Institute of Molecular Medicine, University of Düsseldorf, Universitätsstrasse 1, Düsseldorf 40225, Germany

*Corresponding author: RU Jänicke, Institute of Molecular Medicine, University of Düsseldorf, Building 23.12, Universitätsstrasse 1, Düsseldorf D-40225, Germany. Tel: + 492118115973 ; Fax: + $492118115892 ;$ E-mail: janicke@ uni-duesseldorf.de

Keywords: apoptosis; DNA repair; oxidative stress; survival pathways; transcription factor; tumorigenesis

Abbreviations: UV, ultraviolet; OGG1, 8-oxoguanine-DNA glycosylase; NER, nucleotide excision repair; MMR, mismatch repair; BER, base excision repair

Received 06.12.07; revised 08.2.08; accepted 18.2.08; Edited by RA Knight; published online 21.3.08 
Table 1 Anti-apoptotic p53 targets

\begin{tabular}{|c|c|c|}
\hline p53 targets & Refs & Anti-apoptotic mechanisms \\
\hline \multicolumn{3}{|l|}{ DNA repair } \\
\hline $\begin{array}{l}\text { Mismatch repair (MMR) targets transcriptionally regulated by p53: } \\
\text { MLH1 (homolog of MutL 1) } \\
\text { PMS2 (postmeiotic segregation increased 2), } \\
\text { MSH2 (homolog of MutS 2) }\end{array}$ & 11,12 & $\begin{array}{l}\text { Pro- and anti-apoptotic; cleavage of MLH1 by caspase-3 } \\
\text { produces a pro-apoptotic C-terminal fragment. }\end{array}$ \\
\hline $\begin{array}{l}\text { Nucleotide excision repair (NER) targets transcriptionally regulated } \\
\text { by p53: } \\
\text { p48 (DDB2/XPE), } \\
\text { XPC (xeroderma pigmentosum complementation group C) }\end{array}$ & 13,14 & $\begin{array}{l}\text { Apoptosis inhibition by p48 correlates with inhibition of p38 } \\
\text { activity and induction of c-FLIP expression. }\end{array}$ \\
\hline $\begin{array}{l}\text { Base excision repair (BER) targets regulated by p53 through direct } \\
\text { binding: } \\
\text { APE/Ref-1 (apurinic/apyrimidinic endonuclease-1/redox factor-1), } \\
\text { OGG1 (8-oxoguanine-glycosylase), } \\
\text { pol } \beta \text { (DNA polymerase } \beta \text { ) }\end{array}$ & $15-17$ & $\begin{array}{l}\text { Binding to p53 enhances their activities; APE/Ref-1 } \\
\text { enhances DNA binding of NF- } \kappa \text { B and p53; OGG1 is a } \\
\text { caspase substrate. }\end{array}$ \\
\hline \multicolumn{3}{|l|}{ Cell cycle control } \\
\hline p21 & 18 & $\begin{array}{l}\text { Direct binding and inhibition of CDKs, caspase-3 and } \\
\text { ASK1; interaction with transcription factors. }\end{array}$ \\
\hline 14-3-3 $\delta$ & $\begin{array}{l}19 \\
20,21\end{array}$ & Sequestration of CDKs, Bad, Bax, FoxO3, and ASK1. \\
\hline $\begin{array}{l}\text { PIk2 (Polo-like kinase 2) } \\
\text { BTG2 and BTG3 (B-cell translocation gene } 2 \text { and 3) }\end{array}$ & $\begin{array}{l}20,21 \\
22,23\end{array}$ & $\begin{array}{l}\text { unknown } \\
\text { Inhibition of cyclin D1 and cyclin E expression and E2F } \\
\text { activity. }\end{array}$ \\
\hline \multicolumn{3}{|l|}{ Oxidative stress response } \\
\hline ALDH4 (Aldehyde dehydrogenase 4) & 24 & Anti-oxidant enzyme. \\
\hline MnSOD (Manganese superoxide dismutase) & 25 & $\begin{array}{l}\text { Anti-oxidant enzyme; reciprocal downregulation between } \\
\text { p53 and MnSOD. }\end{array}$ \\
\hline GPX (glutathione peroxidase) & 25,26 & Anti-oxidant enzyme. \\
\hline PA26 (SESN1) and Hi95 (SESN2) & 27,28 & Anti-oxidant enzymes. \\
\hline TIGAR (p53-induced glycolysis and apoptosis regulator) & 29 & Inhibition of glycolysis and ROS production. \\
\hline \multicolumn{3}{|l|}{ Transcription factors } \\
\hline Slug & 30 & Transcriptional repressor of Puma. \\
\hline NF- $\kappa$ B via DRAL (downregulated in rhabdomyosarcoma Lim protein) & 31 & $\mathrm{NF}-\kappa \mathrm{B}$ activation. \\
\hline NF- $\kappa$ B via PIDD (p53-induced protein with a death domain) & 32 & $\begin{array}{l}\text { Formation of an NF- } \kappa \text { B-activating PIDDosome with RIP1 } \\
\text { and NEMO. }\end{array}$ \\
\hline$\Delta \mathrm{Np73}$ & 33 & Inhibition of the transcriptional activity of p53. \\
\hline KLF4 (Krüppel-like factor 4) & 34 & Inducer of p21, but repressor of p53 and Bax transcription. \\
\hline \multicolumn{3}{|l|}{ p53-binding proteins: } \\
\hline MDM2 (murine double minute 2) & 35 & E3 ubiquitin ligase that inhibits p53 stability and function. \\
\hline Cop1 (constitutively photomorphogenic 1) & 36 & E3 ubiquitin ligase that inhibits p53 stability and function. \\
\hline Pirh2 (p53-induced protein with a Ring-H2 domain) & 37 & E3 ubiquitin ligase that inhibits p53 stability and function. \\
\hline p53R2 (p53-induced R2 homolog) & 38 & $\begin{array}{l}\text { Induces G2/M arrest; negatively regulates p53 stability and } \\
\text { function; involved in mtDNA synthesis. }\end{array}$ \\
\hline GTSE-1 (G2 and S phase-expressed-1) & 39 & $\begin{array}{l}\text { Induces G2/M arrest; negatively regulates p53 stability and } \\
\text { function; nuclear export of p53. }\end{array}$ \\
\hline Hzf (Hematopoietic zinc finger) & 40 & $\begin{array}{l}\text { Directs p53 specifically to promoters of cell cycle arrest } \\
\text { genes such as p } 21 \text { and } 14-3-3 \delta \text {. }\end{array}$ \\
\hline \multicolumn{3}{|l|}{ Targets involved in MAPK signaling } \\
\hline EGFR (Epidermal growth factor receptor) & 41 & Activation of Akt. \\
\hline HB-EGF (Heparin-binding EGF-like growth factor) & 42 & Activation of the pro-survival EGFR and Akt pathways. \\
\hline DDR1 (Discoidin domain receptor 1 ) & 43 & Activation of Akt and NF- $\kappa$ B. \\
\hline Cox-2 (Cyclooxygenase 2) & 44 & $\begin{array}{l}\text { Modulation of p53 stability; synthesis of prostaglandin; } \\
\text { augmenting Akt activity. }\end{array}$ \\
\hline Wip1 (Wild-type p53-induced phosphatase 1) & 45 & $\begin{array}{l}\text { Inhibition of p53 and p53-stimulating kinases (p38, ATM } \\
\text { and Chk1). }\end{array}$ \\
\hline MKP1 (Mitogen-activated protein kinase phosphatase-1) & 46 & Dephosphorylation and inhibition of p38 and JNK. \\
\hline \multicolumn{3}{|l|}{ Additional p53 targets } \\
\hline Chk2 (Checkpoint kinase 2) & 47 & p53 represses transcription of pro-apoptotic Chk2. \\
\hline DcR1 and DcR2 (TRAIL decoy receptor 1 and 2) & 48,49 & Inhibition of TRAIL-induced apoptosis. \\
\hline Netrin-1 & 50 & Inhibition of apoptosis signaling by dependence receptors. \\
\hline
\end{tabular}

\section{p53 and DNA Repair}

Non-repaired or non-repairable DNA damage induced for instance by IR and most cytotoxic anticancer drugs is the major cause for p53-induced apoptosis. ${ }^{51}$ Therefore, the repair of damaged DNA might be considered an important mechanism that prevents DNA damage-induced cell death. Intriguingly, besides its outstanding roles in the activation of cell cycle checkpoints and apoptosis, p53 plays also a critical role in the repair of damaged DNA. ${ }^{51,52}$ Thereby p53 acts 
either via its transactivation-dependent or independent functions as a coordinator of the DNA repair process and participates in most of the DNA repair systems operative in cells including mismatch repair (MMR), non-homologous end-joining (NHEJ), homologous recombination, nucleotide excision repair (NER), and base excision repair (BER). ${ }^{52}$ For instance, p53 itself can bind various DNA structures nonspecifically and was even shown to bind to the nuclear matrix following genotoxic stress. Moreover, p53 was demonstrated to catalyze reannealing of short stretches of single- and double-stranded DNA and to promote strand exchange between them and, furthermore, to possess an intrinsic $3^{\prime}-5^{\prime}$ exonuclease activity. Thus, as DNA repair processes can be surely considered as being pro-survival mechanisms, it appears that already these transcription-independent activities of p53 on damaged DNA are somehow of an antiapoptotic nature. Whether they are mediated by an active process or merely represent the consequences of recruiting all available p53 to the sites of damaged DNA, thus leaving none or too little behind to activate apoptotic signaling, remains elusive.

Base excision repair. Induction of BER clearly contributes to apoptosis resistance and deficiencies in crucial components of this pathway such as apurinic/apyrimidinic endonuclease-1/redox factor-1 (APE, Ref-1) or DNA polymerase $\beta(\operatorname{pol} \beta)$ cause a p53-dependent pre- and postnatal lethality, respectively, and lead to hypersensitivity toward certain types of DNA-damaging agents. ${ }^{53,54}$ Consistent with this, upregulation of either APE/Ref-1, pol $\beta$ or 8-oxoguanine-DNA glycosylase (OGG1), another enzyme of the BER machinery, is often observed in various cancers and correlates with apoptosis resistance. ${ }^{51,52}$ Although p53 does not transcriptionally control expression of any member of this pathway, it markedly stimulates BER activity in vitro and in vivo in a cell cycle-specific manner and this effect was suggested to be due to its ability to directly interact with APE/ Ref-1, OGG1 and pol $\beta .^{15,16}$ Interestingly, association of p53 with these BER components not only enhances their activities, but also results in a transcription-independent stabilization of $\operatorname{pol} \beta$ as protein levels, but not mRNA levels, of this enzyme were almost undetectable in p53 mutant or p53null cells. ${ }^{17}$ Although there is little doubt that these BER components and p53 mediate apoptosis resistance, exactly how this is achieved is largely unknown, but might involve activation of $\mathrm{NF}-\kappa \mathrm{B}$. In addition, OGG1 appears to be cleaved by caspases during drug-induced apoptosis. ${ }^{55}$ Whether OGG1 cleavage merely occurs to remove an antiapoptotic protein or whether it amplifies the death response by creating a pro-apoptotic fragment as it was reported for the cleavage of the MMR protein MLH1 (see mismatch repair section) is presently unknown.

Non-homologous end joining. The participation of p53 in NHEJ repair processes of DNA double-strand breaks is somehow more complicated as opposing reports exist. ${ }^{52}$ Nevertheless, the fact that the severe cytotoxic effects and embryonic lethality of mice deficient for critical NHEJ components such as Ku70, the regulatory subunit of the DNA-dependent protein kinase (DNA-PK), X-ray repair cross-complementing protein 4 and DNA ligase IV can be rescued by the homozygous deletion of $p 53^{56-58}$ provides some evidence for a possible crosstalk between these pathways. In fact, Ku70 is upregulated following IR via a p53/ATM-dependent pathway ${ }^{59}$ and was shown to specifically inhibit Bax-dependent apoptosis via a direct association with this pro-apoptotic multi-domain protein preventing its mitochondrial translocation and oligomerization. ${ }^{60}$ Interestingly, Bax can be liberated from Ku70 by a caspase-generated cyclin $E$ fragment resulting in an amplification of the apoptosis signal. ${ }^{61}$ Together, these data suggest an anti-apoptotic role of this DNA repair enzyme that can be controlled in a p53-dependent manner.

Mismatch repair. In addition to these transcriptionindependent mechanisms, p53 transcriptionally upregulates at least in some cell types expression of the MLH1, PMS2 and $M S H 2$ genes ${ }^{11,12}$ whose products critically control the MMR pathway. Although overexpression of many MMRrelated proteins including those described above is sufficient to induce apoptosis, other studies report an increased sensitization following downregulation of MLH1 and $\mathrm{MSH} 2{ }^{52}$ Furthermore, despite the frequent occurrence of inactivating $\mathrm{MSH} 2$ mutations in several sporadic tumors, increased expression of MSH2 mRNA and protein has also been reported in various malignancies indicating an important role for this MMR protein for the pathogenesis and progression of cancer. ${ }^{62}$ In fact, low expression of $\mathrm{MSH} 2$ was found to correlate with an increased overall disease-free survival following therapy. ${ }^{63}$ Also in favor of an anti-apoptotic role of the MMR system is the finding that MLH1 is a caspase-3 substrate whose cleavage creates a pro-apoptotic fragment that by itself is sufficient to induce apoptosis even in the absence of other apoptotic stimuli. ${ }^{64}$ Together with the observation that expression of a non-cleavable MLH1 mutant protein conferred resistance specifically to DNA damageinduced apoptosis, such findings might explain why in several studies the loss of MLH1 (and perhaps also a loss of $\mathrm{MSH} 2$ ) results in resistance toward DNA damaging agents.

Nucleotide excision repair. Finally, the p53-mediated NER response is most likely also mediated through p53-regulated gene products including proteins associated with the cancerprone genetic disease xeroderma pigmentosum, that is, the damage-specific DNA-binding protein 2 (DDB2/p48/XPE) and XPC. ${ }^{65}$ Both proteins are specific constituents of the global genome repair system, a subpathway of NER, and are upregulated by basal and DNA damage-activated p53 in human, but not mouse fibroblasts. ${ }^{13,14}$ Although deficiencies in various NER components were clearly linked to increased apoptosis rates, the genes involved are preferentially associated with transcription-coupled NER, a pathway not or only partially regulated by $\mathrm{p53}$. Mutations or loss of XPC and XPE, on the other hand, mainly correlate with a predisposition to cancer causing apoptosis resistance probably due to an impaired p53 response following UV or cisplatin treatment. ${ }^{52}$ However, previous studies correlated the protective effect of p53 on mouse fibroblasts exposed to UV and several chemotherapeutic agents including cisplatin 
and melphalan with its participation in NER. ${ }^{66}$ It was also shown that overexpression or downregulation of DDB2 correlated with apoptosis resistance or sensitivity of HeLa cells, respectively. Although the mechanisms by which DDB2 mediates apoptosis resistance remain unknown, they appear to be unrelated to its role in DNA repair as a DDB2 mutant that is unable to bind to UV-damaged DNA can still inhibit UV-induced apoptosis. Together with the observation that p53 induces DDB2 expression only in humans, but not in mice, ${ }^{67}$ these findings might help to explain why DDB2deficient mice do not show an increased rate of apoptosis.

Although the previous chapters clearly emphasized the anti-apoptotic potential of several DNA repair-related gene products that are either induced by p53 or that are modulated by binding to p53, a number of those were also shown to induce apoptosis following overexpression. Such opposing findings could be interpreted in several ways: firstly, this death might occur in a p53-independent manner, possibly involving endoplasmic reticulum stress. Alternatively, it is highly questionable that p53 is able to induce those non-physiological levels of DNA repair proteins that are achieved via overexpression. Such an artificial high abundance of these proteins in the absence of any DNA damage might then be mistaken by p53 as excessive DNA damage provoking p53 to transmit apoptotic signals.

\section{p53 and Cell Cycle Control}

Depending on cell type and severity of a stimulus, p53 inhibits progression through the cell cycle in various phases to ensure proper repair of damaged DNA. Whereas the p53-dependent G1-arrest is mainly mediated via induction of the cyclindependent kinase (CDK) inhibitor p21, ${ }^{18}$ the control of the G2 checkpoint by $\mathrm{p} 53$ depends on induction of $14-3-3 \delta .{ }^{68}$ As cell cycle arrest protects cells from apoptosis, at least temporally, it was not too surprising to learn that both p21 and 14-3-3 $\delta$ exert potent anti-apoptotic activities affecting a multitude of different pathways. In addition, an array of different genes involved in cell cycle regulation were found to be transcrip-

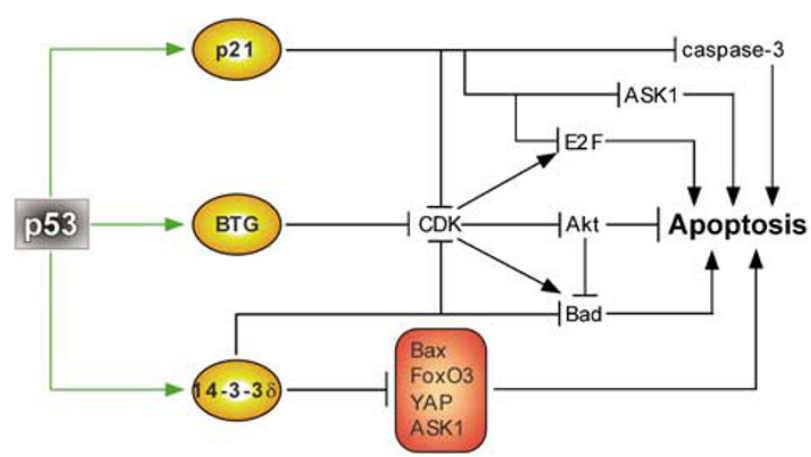

Figure 1 Anti-apoptotic p53 targets involved in cell cycle control. p53 transcriptionally induces (green arrows) expression of the indicated cell cycle regulatory proteins (yellow ovals) that inhibit apoptosis via the indicated pathways. For a better understanding of the anti-apoptotic mechanisms mediated by p21, please refer to reference. ${ }^{69}$ BTG (B-cell translocation gene); CDK (cyclin-dependent kinase); ASK1 (apoptosis signal-regulating kinase 1) and YAP (Yes-associated protein) tionally controlled by p53 (Table 1 ) and most of them are also strongly implicated to act in a pro-survival manner (Figure 1). Because we have very recently discussed the multiple cell death pathways battled by anti-apoptotic p21, ${ }^{69}$ we focus here on the remaining p53-induced cell cycle regulatory proteins mentioned below.

14-3-38. The 14-3-3 proteins are a family of phosphoserine/ phosphothreonine-binding molecules that control the function of a wide array of cellular proteins involved in cell cycle control, signal transduction, protein trafficking, malignant transformation and apoptosis. In humans, there exist at least seven isoforms of which 14-3-3 $\delta$ has been directly implicated in the etiology of cancer. ${ }^{70}$ Due to promoter methylation, $14-3-3 \delta$ protein levels are significantly reduced or negligible in various transformed cell lines and primary tumors indicating tumor suppressor properties that are mainly based on its cell cycle regulatory functions. ${ }^{71}$ Interestingly, this hypermethylation was even observed in normal adjacent breast tissue surrounding the tumor, but not in control tissue from cancer-free patients, indicating that gene silencing of $14-3-3 \delta$ might be an early event during breast carcinogenesis. Together with the observation that silencing of $14-3-3 \delta$ constitutes a single step that can immortalize primary epithelial cells, ${ }^{72}$ these findings emphasize the crucial role of $14-3-3 \delta$ as a tumor suppressor. In contrast, 14-3-3 proteins were also often found overexpressed in various cancers, but the significance of these increases to cancer development has not been firmly established yet. ${ }^{73}$ Nevertheless, $14-3-3 \delta$ is specifically induced by p53 in response to DNA damage ${ }^{19}$ and exhibits multiple and potent anti-apoptotic activities. In fact, loss of 14-3-3 $\delta$ protein expression sensitizes tumor cells to conventional anticancer therapies leading to a massive induction of cell death by mitotic catastrophe, ${ }^{74}$ an apoptotic program dependent on active caspases. Interestingly, the sensitivity of $14-3-3 \delta$-deficient cells is even further enhanced by the simultaneous depletion of $\mathrm{p} 21^{75}$ indicating that both proteins target individual pathways.

Although the pathways affected are diverse, the mechanisms by which 14-3-3 proteins mediate their anti-apoptotic functions mainly involve binding and sequestration of proapoptotic proteins that have been phosphorylated by Akt. For instance, in the presence of survival factors, the pro-apoptotic $\mathrm{Bcl}-2$ member Bad is phosphorylated by Akt and protein kinase $A$. These modifications induce binding to 14-3-3 proteins that retain $\mathrm{Bad}$ in the cytoplasm preventing it from binding to anti-apoptotic $\mathrm{Bcl}-\mathrm{x}_{\mathrm{L}}$ and $\mathrm{Bcl}-2$ proteins at the mitochondria and thereby from exhibiting its death-inducing function. ${ }^{76}$ Genetic knockout studies, however, do not support a crucial role for Bad in DNA damage-induced apoptosis, because Bad-deficient mice develop essentially normal and do not show enhanced resistance to $\gamma$-irradiation or anticancer drugs as it was observed for Puma-deficient mice. ${ }^{77,78}$ Moreover, weaker killers such as Bad engage only a subset of pro-survival proteins, whereas the strong and crucial apoptosis mediator Puma interacts with all of them. ${ }^{7}$ Nevertheless, 14-3-3 was found to disable also the activities of other proapoptotic proteins following their phosphorylation by Akt including those of the forkhead transcription factor FKHRL1, 
the Yes-associated protein (YAP) and apoptosis signalregulating kinase-1 (ASK1). ${ }^{70}$ In a phosphorylation-independent manner, 14-3-3 proteins also interact directly with and inhibit other $\mathrm{BH} 3-$ domain containing proteins such as Bax and even the binding of $14-3-3 \delta$ specifically to CDKs was reported. ${ }^{71}$ As 14-3-3 proteins were also shown to interact with anti-apoptotic factors such as the zinc finger protein A20, the catalytic subunit of telomerase and several others, ${ }^{70}$ whereupon their pro-survival functions are enhanced, these observations clearly demonstrate the versatile mode of action of anti-apoptotic 14-3-3 proteins.

Polo-like kinases. With the regulation of Polo-like kinases (Plks), p53 appears to possess another powerful handle to modulate apoptosis sensitivity in either direction. Plks are a highly conserved family of multi-functional serine/threonine kinases that participate in cell cycle regulation and cellular response to stresses such as DNA damage. ${ }^{79}$ Owing to the activation of components of the anaphase-promoting complex and regulation of the CDK-activating phosphatase Cdc25C, Plk1 and Plk3 critically control several checkpoints during mitosis and cytokinesis, partially in an opposing manner. The influence of Plk2 on the cell cycle, in contrast, is only barely characterized although this kinase is activated following DNA damage by a mitotic checkpoint. Thus, it is conceivable that their deregulation causes genomic instability leading either to tumorigenesis or to mitotic catastrophe. In accordance with their opposing roles in cell cycle control, Plk1 is often overexpressed in a number of different tumors correlating with increased proliferation rates and its downregulation causes massive apoptosis, whereas the opposite scenarios were observed for Plk3. ${ }^{79}$ Although it is completely unknown whether p53 regulates their expression, based on the facts that Plk1 is inhibited in response to DNA damage, whereas Plk3 is activated, it is tempting to speculate that both kinases participate in p53mediated apoptosis signaling. In support of this are also data showing that their regulation upon DNA damage depends on ATM and that p53 is a target for both kinases that are able to bind to and inhibit (Plk1) and activate (Plk3) p53, respectively. ${ }^{79}$ In addition, similar to Plk1, downregulation of SAK (Snk/Plk-akin kinase), a novel polo-like kinase, strongly sensitized cells to p53-induced apoptosis and SAK gene repression was found to be mediated in a p53dependent manner through recruitment of histone deacetylases. ${ }^{80}$

In contrast to Plk1, SAK and Plk3, a completely different picture emerged with regard to the role of p53 in Plk2 signaling. The plk2 gene was found to contain a radiationresponsive p53-binding element ${ }^{20}$ and expression of Plk2 was induced in a p53-dependent manner in response to IR. ${ }^{21}$ More importantly, silencing of Plk2 expression in the presence of mitotic inhibitors was followed by an increase in apoptosis. Although Plk2 is expressed predominantly in G1, apoptosis occurred only during mitosis indicating that $p 53$ responds to a mitotic checkpoint. Thus, in addition to its anti-apoptotic role in $\mathrm{G} 1$ and $\mathrm{G} 2$ cell cycle phases, p53 was proposed to also prevent genomic instability by stalling progression through mitosis and by actively inhibiting mitotic catastrophe through the induction of Plk2. ${ }^{21}$ The mechanism(s), however, by which
Plk2 contributes to apoptosis resistance is completely unknown.

B-cell translocation genes 2 and 3 (BTG2 and BTG3). BTG2 (TIS21, PC3) and BTG3 (ANA) belong to a family of proteins endowed with potent anti-proliferative properties. ${ }^{81}$ Although at least BTG2 was initially identified as an early response gene important for neuronal differentiation, it has now become apparent that both genes contain a p53 consensus sequence and are transcriptionally upregulated by DNA-damaging agents in a p53-dependent manner. ${ }^{22,23}$ Both BTG2 and BTG3 were shown to protect cells from a variety of DNA-damaging insults ${ }^{23,81}$ and these anti-apoptotic activities appear to be closely related to their anti-proliferative effects. Whereas BTG2 blocks G1/S-phase progression through inhibition of cyclinD1 transcription or cyclinE downregulation, ${ }^{81}$ BTG3 is mainly associated with the maintenance of the G2/M-checkpoint by inhibiting the transcriptional activities of E2F family members. ${ }^{23}$ As several cyclins and especially E2F transcription factors have long been implicated to contribute to apoptosis induction, it is conceivable that BTG2 and BTG3 protect cells from DNA damage-induced apoptosis via repressing the activities of these cell cycle-regulatory proteins. In addition, both BTG proteins bind various components of different signaling pathways including several transcription factors that are able to modulate DNA damage-induced stress responses. ${ }^{81}$ Interestingly, TOB, another member of this family whose lack predisposes cells to cancer development ${ }^{82}$ appears to be downregulated by $\mathrm{p} 53$. Although this observation strongly hints in favor of an oncogenic and anti-apoptotic p53, the underlying mechanisms and the impact of TOB overexpression on apoptosis sensitivity were not yet thoroughly investigated.

\section{p53 and the Oxidative Stress Response}

Reactive oxygen species (ROS) are potent activators of p53. ${ }^{83}$ ROS-mediated DNA damage can activate p53 not only directly, but also indirectly due to a considerable crosstalk with other ROS-activated signaling pathways such as the MAPK pathways that in turn regulate p53 activity. ${ }^{83,84}$ ROS are not only generated as a cellular response to exogenous stress stimuli, but also as byproducts of normal aerobic metabolism, or as second messengers in various signal transduction pathways. In addition, ROS are even generated downstream of p53 most likely by the transcriptional modulation of genes that regulate the cellular redox state and that directly contribute to p53-mediated cell death such as Bax and $B B C 3$ (encoding Puma). Although apoptosis occurs also in the absence of ROS, such a positive feedback loop may be important in achieving a critical threshold of ROS leading to the commitment to apoptosis. To maintain the cellular redox state, ROS levels need to be tightly controlled, a task which is performed by two mutually interconnected systems: the thioredoxin and the glutathione system. ${ }^{85}$ Intriguingly, p53 was recently demonstrated to positively regulate expression of genes whose products are directly involved in both systems and owing to this, p53 clearly acts in an anti-apoptotic manner. This list of genes includes the glutathione peroxidase (GPX), 


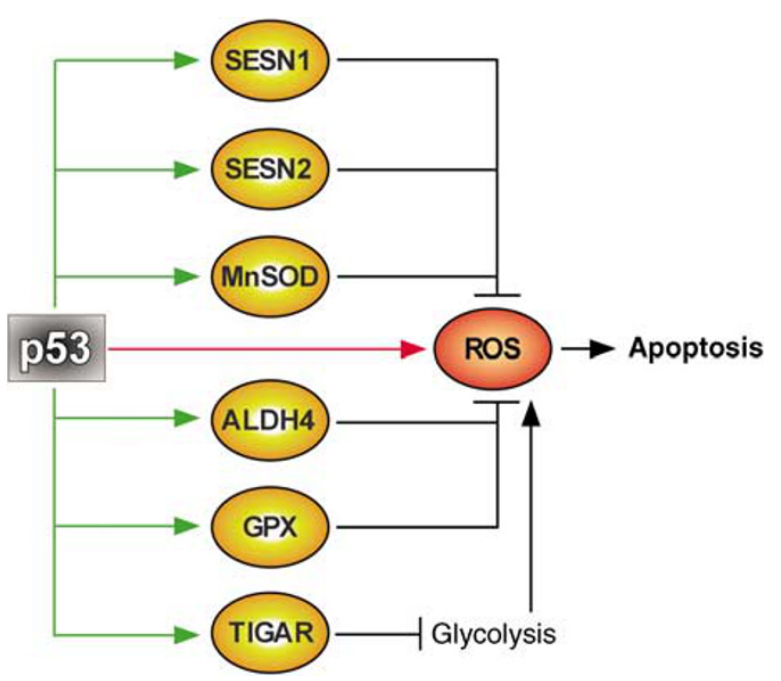

Figure 2 Anti-apoptotic p53 targets involved in oxidative stress responses. p53 transcriptionally induces (green arrows) expression of the indicated anti-oxidant enzymes (yellow ovals) that negatively control the production of reactive oxygen species (ROS). The fact that p53 can also induce ROS production is indicated by a red arrow. ALDH4 (aldehyde dehydrogenase 4); GPX (glutathione peroxidase); MnSOD (manganese superoxide dismutase); SESN1/2 (sestrin1/2) and TIGAR (p53-induced glycolysis and apoptosis regulator)

manganese superoxide dismutase (MnSOD, SOD2), aldehyde dehydrogenase 4 (ALDH4), p53-induced glycolysis and apoptosis regulator (TIGAR), as well as PA26 and Hi95 that encode two proteins of the sestrin family, namely sestrin 1 (SESN1) and sestrin 2 (SESN2), respectively (Figure 2).

Aldehyde dehydrogenase 4. ALDH4 is a mitochondrialmatrix $\mathrm{NAD}^{+}$-dependent enzyme that catalyzes the second step of the proline degradation pathway. ${ }^{86}$ Expression of the ALDH4 gene that contains a potential p53-binding sequence in the first intron was induced in response to DNA damage caused by adriamycin treatment and cells engineered to overexpress ALDH4 were protected from death induced by hydrogen peroxide. ${ }^{24}$ Consistently, inhibition of ALDH4 expression resulted in an increased ROS production and enhanced cell death induced by p53 overexpression. Because p53 also controls expression of the ALDH4 antagonizing enzyme proline oxidase (POX, also known as p53-inducible gene 6, PIG6), ${ }^{87}$ it appears that the balance of these two opposing enzymes might be critical for p53dependent apoptosis, ${ }^{24}$ a hypothesis that still awaits its experimental validation.

Manganese superoxide dismutase. Several apoptosis systems induced for example by death receptor ligands, IR, anti-cancer drugs and of course oxidative stress were efficiently counteracted by mitochondrial MnSOD, ${ }^{88}$ another antioxidant enzyme regulated by $p 53 .{ }^{25}$ Based on these and many other reports clearly validating MnSOD as a negative modulator of cellular apoptosis and hence, as a survival factor for cancer cells, it was postulated that pharmacological inhibition of MnSOD may represent an effective strategy to selectively kill cancer cells. ${ }^{88}$ However, elevated MnSOD protein levels were also correlated with increased oxidative stress and apoptosis induction. ${ }^{25}$ Although contradictory, oxidative stress and apoptosis can be also caused by an antioxidant imbalance. ${ }^{89}$ Indeed, while Hussain et al. ${ }^{25}$ observed the p53-dependent increase in MnSOD and GPX expression, catalase levels and activity remained unaffected. Thus, they hypothesized that in the absence of elevated catalase activity, the levels of GPX are apparently not sufficient to detoxify the entire hydrogen peroxide pool generated by MnSOD resulting in apoptosis. ${ }^{25}$ Evidently, such an antioxidant imbalance obtained by upregulation of MnSOD was also recently postulated to contribute to its potential tumor suppressive function. ${ }^{88}$ Furthermore, similar to other pathways induced by p53, there appears to exist a reciprocal downregulation of $\mathrm{p} 53$ and MnSOD gene expression leading to a fine tuning of p53 activity. ${ }^{90}$ Although this gene repression was associated with reduced promoter activity in both cases, exactly how p53 and MnSOD affect each other's expression remains to be elucidated.

Glutathione peroxidase. Also the GPX gene was classified as a direct p53 target as it contains p53-binding sites in its promoter resulting in a p53-dependent expression. ${ }^{25,26}$ Like MnSOD, overexpression of GPX protected cells against various DNA-damaging insults ${ }^{91,92}$ and, consistent with the idea that apoptosis is also induced by an antioxidant imbalance, was shown to abrogate the tumor suppressive function of MnSOD. ${ }^{93}$ The cytoprotective effect was also achieved with the GPX mimic 2-selenium-bridged betacyclodextrin that, in addition, yielded by an as yet unknown mechanism in inhibition of p53 expression indicating that also GPX might act in a negative feedback loop controlling p53 activity. ${ }^{94}$ Interestingly, $\Delta \mathrm{Np} 63 \gamma$, another member of the p53 family, was shown to specifically induce expression of the GPX2 isoenzyme that inhibited oxidative stress-induced apoptosis in a p53-dependent manner. ${ }^{95}$ Thus, with the tight regulation of pro- and anti-oxidative components, p53 (and family members) appears to be a crucial determinant in the control of the cellular redox state.

SESN1 and SESN2. In two independent studies, two novel genes, PA26 and Hi95, were identified whose expression was upregulated in a p53-dependent manner following DNA damage. ${ }^{27,28}$ Interestingly, whereas overexpression of the Hi95 cDNA was found to be toxic for many cell types, its conditional overexpression resulted in protection against hypoxia- or $\mathrm{H}_{2} \mathrm{O}_{2}$-induced apoptosis indicating that $\mathrm{Hi95}$ is involved in the complex regulation of cell viability in response to different stress conditions. Although initially no function could be assigned to PA26, based on the strong homology to $\mathrm{Hi95}$ that led to their common classification as sestrins, it was assumed that both exert related functions in cellular stress responses. Indeed, it was found that PA26 (SESN1) and Hi95 (SESN2) are essential components in the regeneration process of peroxiredoxins, ${ }^{96}$ a family of thioredoxindependent peroxidases. Together with thioredoxins, peroxiredoxins maintain the cellular reducing environment by scavenging intracellular hydrogen peroxide, a function that is clearly involved in protection from p53-induced apoptosis. In addition, various other members of the thioredoxin system were shown to prevent apoptosis by 
several means. ${ }^{97}$ Thus, by upregulating PA26 and Hi95 expression, p53 is able to induce a strong anti-apoptotic response whose physiological implications have been elucidated only recently. ${ }^{98}$ In this elegant study, the authors demonstrated that in the absence of severe stresses, relatively low p53 levels were sufficient for upregulation of several antioxidant genes including GPX, SESN1 and SESN2 correlating with a decrease in intracellular ROS levels. In contrast, elevated ROS production was only observed in heavily stressed cells upon induction of the p53 targets Bax and Puma that, however, might only be a consequence of cells dying rather than its cause. In addition, they found that the increased DNA oxidation and mutagenesis rates and even neoplasia development common for p53-deficient cells and mice were substantially prevented following overexpression of sestrin genes or when p53-deficient mice were maintained on a diet supplemented with the antioxidant compound $\mathrm{N}$-acetylcysteine (NAC). Thus, the antioxidant function of p53 represents an important component of its tumor suppressor activity, which decreases the probability of genetic alterations and assists the survival and repair of cells with minor injuries. However, several questions remain as it was for example not addressed whether NAC supplementation is also effective in animals with established tumors, and whether such a treatment might also prove chemopreventive on p53-positive preneoplastic lesions. Nevertheless, with the induction of these anti-oxidant genes, p53 controls a powerful antiapoptotic network that is able to counteract stress-induced oxidative damage.

TIGAR. p53 intervenes with ROS metabolism also by other means, namely by induction of TIGAR. ${ }^{29}$ Based on two p53binding sites upstream of the first exon and within intron 1, TIGAR was shown to be upregulated rapidly in a p53dependent manner following adriamycin treatment. Interestingly, TIGAR protein shares sequence similarities with 6-phosphofructo-2-kinase/fructose-2,6-bisphosphatase (PFK-2/FBPase-2), a bifunctional enzyme with both kinase and bisphosphatase activities crucially involved in glycolysis. As the similarity between TIGAR and PFK-2/FBPase-2 is mainly restricted to the bisphosphatase domain that in contrast to its kinase domain inhibits glycolysis, it was anticipated that TIGAR may function as a fructose bisphosphatase rather than a kinase. Indeed, whereas overexpression of TIGAR resulted in a reduction of glycolysis, its knockdown increased glycolytic rates. More importantly, concomitant with lowered glycolytic rates, TIGAR also prevented the generation of ROS and subsequently protected cells from apoptosis induced by ROS, but had no effect on ROS-independent apoptosis systems such as CD95. Conversely, loss of TIGAR resulted in an increase in basal and adriamycin-induced ROS levels and sensitized cells to apoptosis induced by oxidative stress. Thereby, TIGAR might not only contribute to p53's multiple anti-apoptotic activities by directly decreasing ROS levels, but also indirectly due to its involvement in DNA repair. This is because NADPH and ribose-5-phosphate that are intermediate metabolites of the alternative pentose phosphate pathway instigated by an increased FBPase-2 (or TIGAR) activity are important precursors of DNA biosynthesis and repair. ${ }^{99}$ Despite acting as an antiapoptotic protein, with the inhibition of glycolysis TIGAR might be also involved in the tumor suppressive functions of p53 $3^{100}$ as cancer cells preferentially utilize glycolytic pathways for energy generation while downregulating their aerobic respiratory activity.

Remarkably, this novel metabolic function of p53 appears to be not restricted to the induction of TIGAR, as also two other proteins, SCO2 (synthesis of cytochrome $c$ oxidase-2) and PGM (phosphoglycerate mutase), both of which are involved in glycolysis, are regulated by p53. ${ }^{101,102}$ However, although p53 was implicated to serve as a metabolic sensor capable of coordinating a reversible cell cycle arrest in response to glucose deprivation, ${ }^{103}$ it has not been elucidated yet whether and to what extent these proteins contribute to this survival pathway.

\section{p53 and Transcription Factors}

Slug. Although it is well established that apoptosis induction by p53 critically depends on transcriptional activation of several p53 target genes including Bax, Noxa, and other p53-induced genes, genetic knockout approaches targeting individual genes commonly delivered only a disappointing partial protection from p53-dependent apoptosis. A major breakthrough was achieved with the discovery that merely the elimination of the p53-upregulated modulator of apoptosis (Puma), a pro-apoptotic BH3-only member of the $\mathrm{Bcl}-2$ family, is sufficient to protect thymocytes from IRinduced cell death to the same extent as similar treated p53-deficient thymocytes. ${ }^{78}$ However, this finding could not answer the long debated question why for instance thymocytes are effectively killed by IR, whereas other cells including hematopoietic progenitors are protected from the same insult. An important clue was provided with the discovery that Slug, a member of the highly conserved Slug/Snail family of transcription factors, protected hematopoietic progenitor cells from radiation- and druginduced apoptosis. ${ }^{104}$ As Slug expression appears to be confined to multiple subsets of hematopoietic progenitors and absent in more differentiated myeloid cells or pro-B and T-cells, these findings provided an elegant explanation why the former, but not the latter cell populations are protected from genotoxic stress. ${ }^{105}$ Intriguingly, Slug was recently shown to be a direct transcriptional target of p53 antagonizing its pro-apoptotic activities. ${ }^{30}$ Both mouse and human slug genes were found to each contain two p53-responsive elements residing in the first and second introns and both were specifically bound and transactivated by $\mathrm{p} 53$.

How does Slug protect cells from p53-mediated apoptosis? Slug acts as a transcriptional repressor specifically inhibiting the promoter activity of Puma following exposure of cells to IR, but not that of Noxa (Figure 3). ${ }^{30}$ Interestingly, both the Slug and the p53-binding sites were identified within intron 1 sequences of puma suggesting a direct inhibition of p53-mediated Puma induction. Slug appears to be a critical and specific modulator of the p53-induced Puma-mediated 


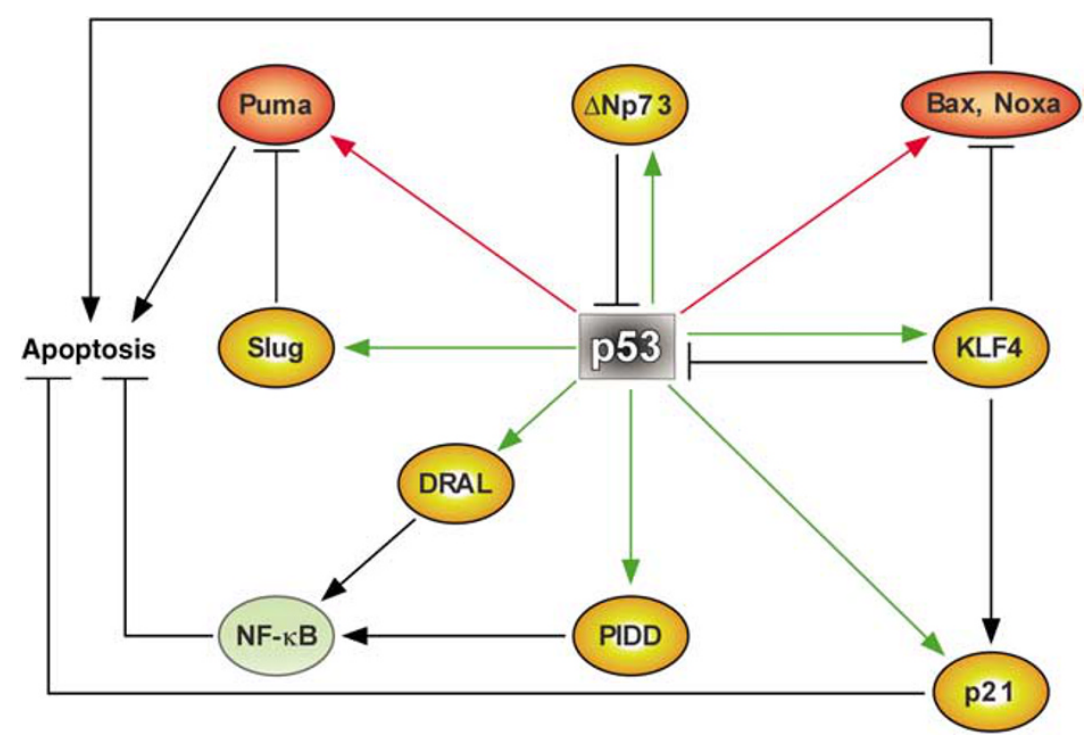

Figure 3 Anti-apoptotic p53 targets that act as transcription factors. p53 transcriptionally induces (green arrows) expression of the indicated transcription factors (yellow ovals) that mediate their anti-apoptotic activities either by negative feedback loops ( $\Delta$ Np73, KLF4), by repressing p53-induced pro-apoptotic (red) proteins (KLF4, Slug) or by activation of the anti-apoptotic (green) transcription factor NF- $\kappa B$ (DRAL, PIDD). The CDK inhibitor p21 is included as it can also interfere with transcriptional processes. ${ }^{69}$ DRAL (downregulated in rhabdomyosarcoma Lim protein); KLF4 ( Krüppel-like factor 4); PIDD (p53-induced protein with a death domain)

stress response preferentially promoting cell cycle arrest and the repair of damaged DNA, as also the p53-mediated transcriptional activation of p21 was not affected by Slug. Indeed the increased radiosensitive phenotype of Slugdeficient mice was rescued by the simultaneous loss of p53 or Puma. It is interesting to note that Slug does not interfere with either the upregulation or transcriptional activation of $\mathrm{p} 53$. Thus, unlike other p53-induced anti-apoptotic proteins that act via downregulation of p53, Slug appears to solely mediate its anti-apoptotic response by repressing transcriptional activation of Puma.

Slug is aberrantly expressed in a number of different tumor types $^{105}$ and mice carrying a tetracycline-repressible slug transgene developed mesenchymal tumors mainly leukemias and sarcomas. ${ }^{106}$ Together, these findings demonstrate a critical role for the anti-apoptotic Slug protein in tumorigenesis. Whether these data can be exploited therapeutically is still uncertain especially based on the knowledge that tumorigenesis provoked by Slug overexpression becomes Slug-independent with time. ${ }^{106}$

Nuclear factor kappa B. The transcription factor Nuclear factor kappa B (NF- $\kappa$ B) can be truly considered as one of the most powerful suppressors of apoptosis known so far and its constitutive activation observed in many cancers has been directly implicated in tumorigenesis, invasion and metastasis. ${ }^{107}$ With the induction of several key players involved in apoptosis inhibition including C-FLIP, Bcl-2 and inhibitor of apoptosis proteins, NF- $\kappa \mathrm{B}$ efficiently counteracts death signaling at crucial crosspoints in both the extrinsic and intrinsic death pathways. ${ }^{108,109}$ In addition, NF- $\kappa$ B directly counteracts the pro-apoptotic function of p53 not only by competing for limited pools of the transcriptional coactivators p300 and CBP, but also via induction of MDM2 probably via the NF- $\kappa \mathrm{B}$ regulator $\mathrm{Bcl}-3 .{ }^{110}$ Although $\mathrm{NF}-\kappa \mathrm{B}$ is activated by
DNA-damaging agents in an ATM-dependent manner, ${ }^{109}$ its direct induction by p53 was not yet unambiguously demonstrated.

Recent studies though clearly demonstrate a direct link between DNA damage-induced p53 activity and NF- $\kappa$ B activation that was surprisingly established with the identification of the pro-apoptotic p53-induced protein with a death domain (PIDD). ${ }^{32}$ PIDD expression was found to be induced by IR in a p53-dependent manner and also the basal level of PIDD positively correlated with the cellular p53 status. Whereas inhibition of PIDD expression attenuated p53induced cell death, PIDD strongly induced apoptosis when overexpressed in p53-deficient cells, suggesting that PIDD acts downstream of $p 53 .{ }^{32}$ Later studies showed that the mitochondrial death pathway induced by PIDD requires formation of a so-called PIDDosome containing the adaptor protein RAIDD (receptor-interacting protein (RIP)-associated ICH/CED-3 homologous protein with a death domain) and pro-caspase-2 that similar to pro-caspase-9 in the apoptosome becomes autocatalytically activated in this oligomerization platform. ${ }^{111}$ Recently, however, an alternative PIDD-containing complex was found upon exposure of cells to genotoxic stress that comprised RIP1 and the NF- $k$ B essential modulator (NEMO), but lacked RAIDD and procaspase-2. ${ }^{112}$ NEMO is a pivotal upstream component in the activation cascade of NF- $\kappa$ B that requires sumoylation by a so far unknown signaling pathway prior to the ATM-dependent phosphorylation and ubiquitination to activate the cytoplasmic $\mathrm{NF}-\kappa \mathrm{B}$-activating IKK complex. Therefore, the formation of a genotoxic stress-induced PIDD-RIP1-NEMO complex intriguingly implicated that p53-induced PIDD might be involved in the activation of NF- $\kappa$ B. Indeed, PIDD was found to mediate stress-induced NF- $\kappa$ B activation through augmenting the levels of sumoylated NEMO and, as a consequence, also its phosphorylation and ubiquitination (Figure 3). ${ }^{112}$ 
Consistently, knockdown of PIDD or RIP1, but not depletion of caspase-2 prevented these posttranslational modifications of NEMO as well as activation of NF- $\kappa \mathrm{B}$.

The puzzling observation that genotoxic stress leads to the formation of two alternative PIDD-containing complexes that engage opposing pathways was resolved very recently. ${ }^{113}$ Here the authors showed that PIDD is constitutively cleaved in an autocatalytic manner into three fragments: PIDD-N (1-445aa), PIDD-C (446-910aa) and PIDD-CC (588-910aa). Whereas PIDD-CC was preferentially found in the RAIDD-containing complex mediating caspase-2 activation, $N F-\kappa B$ was only activated following formation of the RIP1 complex that specifically recruited the PIDD-C fragment. Thus, the cellular fate not only depends on p53 that controls expression of PIDD, but also on post-translational processing events that critically modulate the decision between life and death. Considering, however, that genotoxic stress leads also to the formation of the pro-apoptotic PIDDosome, it is unfortunate that the biological consequences of the PIDD-induced NF- $\kappa$ B activation were not investigated in these studies. Especially based on the notion that NF- $\kappa \mathrm{B}$, besides its powerful anti-apoptotic functions, can also serve as a pro-apoptotic factor, ${ }^{109,110}$ it would be of great interest to learn whether cells are protected from apoptosis or doomed to die upon formation of the PIDD-RIP1-NEMO complex.

An additional pathway connecting $\mathrm{p} 53$ to $\mathrm{NF}-\kappa \mathrm{B}$ was uncovered by the finding that DRAL (for downregulated in rhabdomyosarcoma LIM protein) is a p53-regulated gene containing five putative p53-binding sites in its promoter (Figure 3). ${ }^{31}$ DRAL expression was induced by IR only in cells expressing wild-type, but not mutant p53 in a similar kinetic as p21 indicating an early involvement of this protein in response to cellular stress. Although the original report correlated DRAL with the induction of apoptosis, a later study demonstrated that this protein strongly enhanced TNF receptor-associated factor-2-mediated NF- $\kappa \mathrm{B}$ activation in a dose-dependent manner linking DRAL expression to a pro-survival pathway. ${ }^{114}$ However, it was not investigated whether DRAL can protect cells from p53-induced apoptosis leaving some uncertainties on the actual role of this protein in cellular stress responses.

$\Delta$ Np73. p53 is a member of a transcription factor family that also comprises p63 and p73. ${ }^{115}$ Similar to p53, p63 and p73 are also activated by a broad range of DNA-damaging agents and induce apoptosis via the intrinsic death pathway through transactivation of almost an identical set of genes. However, they do not entirely act in a redundant fashion and each protein was shown to exhibit its own unique functions as determined in transgenic knockout mice. Owing to alternative promoter utilization and mRNA splicing, various isoforms are expressed from each of these members (in addition to the full-length proteins) lacking either a functional $\mathrm{N}$-terminal transactivation (TA) domain and/or C-terminal sequences. ${ }^{116}$ Whereas the full-length isoforms induce apoptosis, the $\Delta \mathrm{N}$ forms lacking the TA mainly act as dominant-negative modulators of the full-length proteins, inhibiting transcription of target genes and induction of apoptosis. This is either achieved by the direct binding of $\Delta \mathrm{N}$ isoforms to their wildtype counterparts or by competition for the DNA-binding sites in which transactivation-inactive $\Delta \mathrm{N}$ isoforms bind promoter elements thereby preventing binding of full-length proteins. Thus, the loci for p53, p63 and p73 encode proteins with both tumor suppressive and putative oncogenic functions.

Intriguingly, p53 strongly induces expression of its antagonist $\Delta \mathrm{Np} 73$ establishing an autoregulatory feedback loop (Figure 3). ${ }^{33}$ Upregulation of the $\Delta \mathrm{Np} 73$ isoform appears to be a frequent event in various cancers that might have contributed to their chemoresistance. ${ }^{117}$ In fact, it represents a poor prognostic marker in patients suffering from neuroblastoma, most likely by inhibiting the apoptotic activities of p53 and p73. ${ }^{118}$ Rather strikingly, the predominant form of p73 in the developing mouse brain is in fact $\Delta \mathrm{Np} 73$ and not wildtype p73 where this isoform is needed to counteract p53mediated neuronal death. ${ }^{119}$ It would now be very interesting to determine whether $p 53$ can also transactivate $\Delta N p 63$ and perhaps even its own $\Delta \mathrm{N}$ isoforms as such events would indeed constitute a critical regulatory switch in the delicate balance of life and death decisions mediated by $p 53$.

Krüppel-like factor 4. Another transcription factor induced by p53 following DNA damage is Krüppel-like factor 4 (KLF4). ${ }^{34}$ KLF4 belongs to a family of zinc finger containing transcription factors that in humans comprises at least 25 members, all of which are critical regulators of various cellular functions including differentiation and proliferation. ${ }^{120}$ Ectopic expression of KLF4 results in sustained cell cycle arrest at both the G1/S and G2/M transition that was postulated to be due to its ability to synergize with p53 to induce p21 expression. ${ }^{34}$ Indeed, ablation of only p21 results in a complete bypass of KLF4-induced cell cycle arrest. ${ }^{121}$ Together with a number of reports demonstrating loss of KLF4 expression in human tumors, particularly in the gastrointestinal tract, and that this loss is associated with a more aggressive cancer phenotype, these observations have implicated KLF4 as a potent tumor suppressor. ${ }^{120}$ However, KLF4 was also found overexpressed in human breast tumors and squamous cell carcinomas. Furthermore, deletion of p21 was not only shown to override KLF4-induced cell cycle arrest, but also collaborated with KLF4 in the oncogenic transformation of mouse embryonic fibroblasts (MEFs). ${ }^{121}$ Thus, it appears that KLF4 is associated with a dual function and may act both as a tumor suppressor and oncogene.

Consistent with its oncogenic role, KLF4 was recently implicated in protecting colorectal cancer cells and MEFs from apoptosis induced by IR and chemotherapeutic drugs. ${ }^{121,122}$ Whereas cells expressing small hairpin RNAs against KLF4 underwent apoptosis following exposure to IR or cisplatin, similarly treated KLF4-proficient cells showed a significant resistance against these stimuli and even resorted to checkpoint arrest. The mechanisms by which KLF4 protects cells from DNA damage-induced apoptosis appear to be multiple and entail for instance direct binding to p53 resulting in a preferential association with the p21 promoter and increased expression of this CDK inhibitor. ${ }^{34}$ Accordingly, in this study KLF4 could not prevent IR-induced apoptosis in HCT116 colon carcinoma cells lacking p21. In contrast, Rowland et al. ${ }^{121}$ were able to obtain in their study sufficient protection from cisplatin-induced apoptosis also in p21-deficient fibroblasts demonstrating that KLF4 mediates 
its anti-apoptotic and oncogenic function also independently of $\mathrm{p} 21$. Instead they revealed a rather unexpected feedback mechanism that controls p53 expression in an autoregulatory manner. Although ectopic expression of KLF4 induced p21, p53 levels dramatically decreased in a proteasome-independent manner. They further showed that KLF4 directly binds to a so-called PE21 element within the proximal region of the p53 promoter, thereby actively repressing transcription of the $p 53$ gene. Together with the observation that KLF4 not only synergizes with p53 in the induction of p21, but simultaneously represses $\mathrm{p} 53$-mediated Bax transcription by directly binding also to this promoter, ${ }^{122}$ these mechanisms of p53 inactivation surely constitute efficient ways to counteract apoptosis (Figure 3). Despite the divergent data obtained in these two studies regarding p21 that might point to an involvement of additional cell type- and stimulus-dependent factors, the role of p21 in the KLF4-mediated protection cannot be completely neglected as it possesses multiple and powerful anti-apoptotic capabilities ${ }^{69}$ that may also contribute to oncogenesis.

\section{p53-Binding Proteins}

Activation of p53 can either result in growth arrest or apoptosis. What determines this decision is still elusive, but a number of different factors are involved including cell type, the specific insult and severity of the damage. ${ }^{1}$ It has also been postulated that the absolute level of $p 53$ protein in a cell that is mainly controlled by diverse post-translational modifications ${ }^{3}$ can modulate the biological effects, with low levels being anti-apoptotic, modest levels inducing growth arrest, and higher levels causing apoptosis. While such a regulation is clearly important, p53 protein levels are not the sole regulatory control on p53 function that most likely depends also upon cofactors that enhance or repress the DNA binding or transactivation functions of $\mathrm{p} 53 .^{123}$ Intriguingly, p53 regulates expression of several p53-binding proteins that in turn negatively interfere not only with its own stabilization and activation, but also with regard to its transactivation function.

Murine double minute 2 (MDM2 or HDM2 in humans). One of the first and probably most intensively studied regulators of p53 stability and function is MDM2, an ubiquitin E3 ligase. ${ }^{124}$ MDM2 is an important regulator of the p53 response, in both the presence and absence of DNA damage, where it plays a critical role in negatively controlling p53 activity (Figure 4). The importance of MDM2 for the control of p53 was especially evidenced by the finding that the embryonic lethality of MDM2-deficient mice could be suppressed by concurrent deletion of p53. In the absence of DNA damage, Mdm2 binds to the $\mathrm{N}$-terminal region of p53 and inhibits its activity by three mechanisms: firstly, by blocking p53-mediated transactivation, secondly, by exporting p53 from the nucleus into the cytoplasm and finally by promoting the proteasomal degradation of $p 53$ through direct ubiquitination. ${ }^{124}$ Upon DNA damage, both p53 and MDM2 become phosphorylated by ATM and checkpoint kinases leading to the dissociation of the p53/MDM2 complex and activation of p53. Because MDM2 transcription is positively regulated by $\mathrm{p53}$, this transcriptional activation provides a negative autoregulatory feedback loop leading to inactivation of p53. ${ }^{35}$ In addition, MDM2 appears to play an important role in the etiology of human cancer as it is amplified or overexpressed in a subset

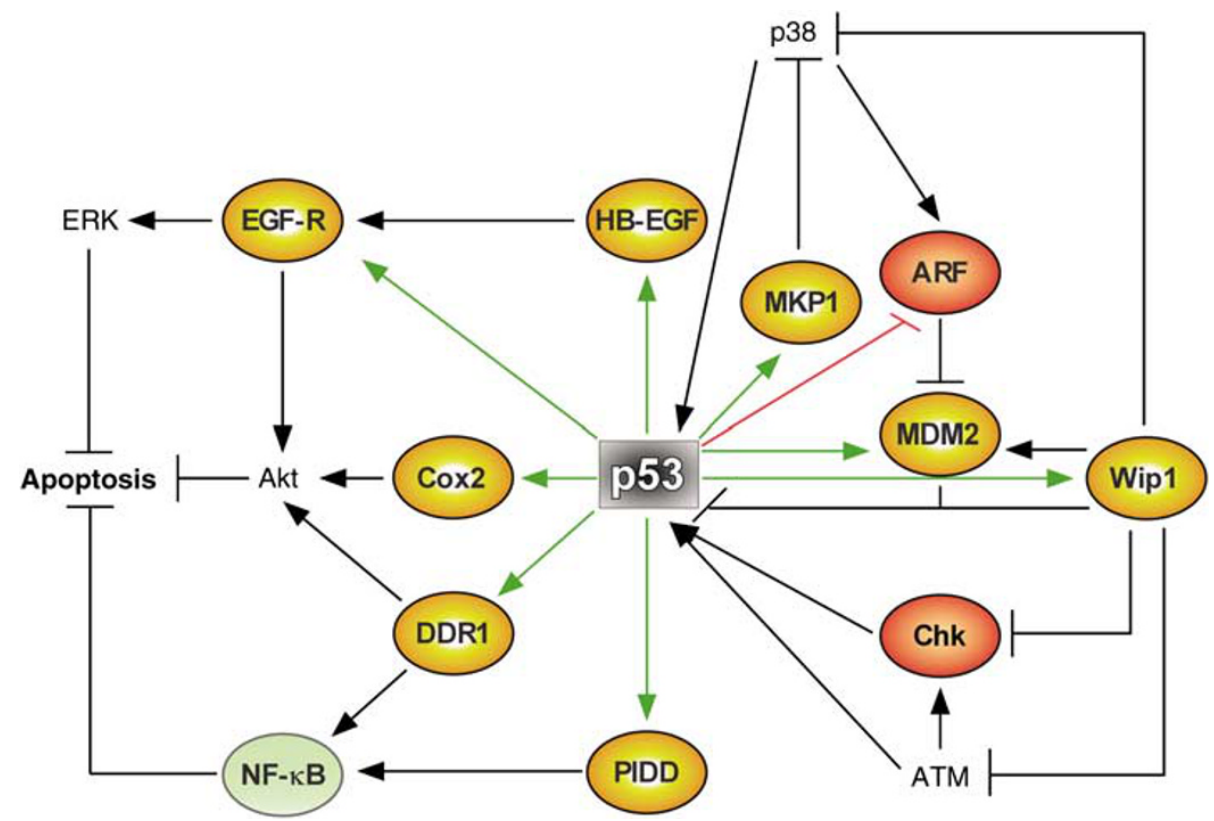

Figure 4 Anti-apoptotic p53 targets involved in MAPK-signaling pathways. p53 transcriptionally induces (green arrows) expression of the indicated proteins (yellow ovals) that mediate their diverse anti-apoptotic activities as indicated. The preferentially pro-apoptotic acting ARF and Chk proteins are displayed in red, whereas the anti-apoptotic NF- $\kappa$ B transcription factor is presented as a green oval. ARF (alternate reading frame); ATM (Ataxia telangiectasia); Chk (checkpoint kinase); Cox2 (cyclooxygenase 2); DDR1 (discoidin domain receptor 1); EGF-R (epidermal growth factor receptor); HB-EGF (heparin-binding EGF-like growth factor); MDM2 (murine double minute 2); MKP1 (mitogenactivated protein kinase phosphatase 1); Wip1 (wild-type p53-induced phosphatase 1) 
of human tumors expressing wild-type p53. Thus, the oncogene MDM2 represents clearly one of the most outstanding p53 targets responsible for keeping p53's functions tightly in check. Interestingly, several p53 targets discussed in this review that negatively affect p53 function and hence act in an anti-apoptotic manner were shown to destabilize p53 by interfering with the MDM2 pathway.

Cop1 (constitutively photomorphogenic 1) and Pirh2 (p53-induced protein with a Ring-H2 domain). As p53 ubiquitination was not completely abolished in extracts from MDM2-deficient cells, the existence of other molecules capable of targeting p53 for degradation was suggested. ${ }^{125}$ Indeed, it was found that p53 can also be targeted for proteasomal degradation by three other E3-ubiquitin ligases namely Cop1, Pirh2 and synoviolin, from which the former two are regulated in a p53-dependent manner following IR. ${ }^{36,37}$ Similar to the effects observed with increased MDM2 levels, overexpression of either Cop1 or Pirh2 resulted in the proteasomal destruction of p53 and concomitantly protected the cells from growth inhibition and apoptosis. Accordingly, experiments using siRNAs against MDM2, Pirh2, or Cop1 showed that the loss of each could independently enhance p53's half-life with coordinate increases in p53 transcriptional activity sensitizing cells to IR-induced apoptosis. Interestingly, downregulation of Cop1 in vivo was recently demonstrated to occur via a rapid autodegradation mechanism instigated by phosphorylation through DNA damage-induced ATM. ${ }^{126}$ As simultaneous introduction of the Cop1 siRNA with either the siRNA for MDM2 or Pirh2 resulted in a synergistic effect on p53 stability, these results indicate that the three p53-regulated E3-ubiquitin ligases do not merely act in an entirely redundant fashion. This view was further supported by the finding that Pirh2, in contrast to MDM2, was only upregulated in response to IR, but not following UV treatment although both contain p53-binding sites in their promoters (Cop1 induction by UV was not investigated). Interestingly, a similar differential expression of p53-responsive genes was recently observed following exposure of E1A-transformed MEFs to UV and IR. Whereas Puma expression was heavily induced in these cells by IR, UV treatment resulted only in the induction of Noxa, but not Puma whose expression was most likely suppressed by a p53-independent upregulation of Slug. ${ }^{127}$

MDM2 and Pirh2 (and most likely also Cop1) appear to associate with different regions in the p53 protein. Whereas MDM2 interacts with its $\mathrm{N}$-terminal transactivation domain, Pirh2 most likely binds p53 in its central DNA-binding domain. ${ }^{37}$ Although the p53 region responsible for Cop1 binding was not mapped, it is likely that this association occurs also at a site distinct from the MDM2-binding domain as a p53 antibody known to abolish p53/MDM2 interaction did not abrogate Cop1 binding. ${ }^{36}$ Thus, dependent on the circumstances, MDM2, Cop1 and Pirh2 might act independently from each other, an attractive possibility especially in view of the fact that various $\mathrm{N}$-terminal deleted p53 isoforms exist that cannot be controlled by MDM2. ${ }^{116}$ Alternatively, these ligases might even require each other's presence to fully unfold their p53-controlling capabilities, an assumption that would help to explain the puzzling finding why Cop1 and Pirh2 cannot compensate the lack of MDM2 that results in embryonic lethality. ${ }^{128}$ Whatever the answer might entail, the observation that both E3 ubiquitin ligases are frequently overexpressed in a variety of cancers ${ }^{129,130}$ implies a similar oncogenic potential for these enzymes as it was demonstrated for MDM2. Nevertheless, several questions remain to be investigated including the mechanisms that determine the binding of p53 to Cop1 and Pirh2 before a more definite picture can emerge on their role in p53 signaling.

p53-induced R2 homolog. The p53-induced R2 homolog (P53R2) gene contains a p53-binding sequence in intron 1 and encodes a 351 amino acid peptide that shows striking similarity to ribonucleotide reductase small subunit (R2) that catalyzes conversion of ribonucleoside diphosphates to the corresponding deoxyribonucleotides to provide a balanced supply of precursors for DNA synthesis and repair. p53R2 expression was induced by DNA damage in a p53-dependent manner. ${ }^{38}$ Expression of p53R2 in p53-deficient cells caused G2/M arrest and prevented cell death in response to adriamycin, whereas p53R2 downregulation in cells with an intact p53-dependent DNA damage checkpoint reduced DNA repair and cell survival. P53R2-/- mice initially develop normal until weaned, but thereafter display signs of growth retardation and early mortality. ${ }^{131}$ These mice die by the age of 14 weeks due to severe multiple organ and renal failure correlating with an increased stability and activation of p53 resulting in the induction of pro-apoptotic p53 target genes such as Bax and Noxa and an increased apoptosis rate. Especially the latter observation indicated that p53R2, in addition to its essential role in DNA repair, might be also directly involved in modulating p53 stability and activity. However, although p53R2 was shown to physically interact with p53, a function that appears to be required for the supply of dNTPs for DNA repair, the additional mechanism(s) by which p53R2 keeps p53 in check is still unknown.

An interesting twist to this story was provided with the finding that in the absence of DNA damage p53R2 binds also to p21 and this association facilitates nuclear accumulation of both proteins. ${ }^{132}$ In response to UV, however, this binding decreased resulting not only in an increase of the ribonucleotide reductase activity of p53R2, but also in an increased binding of p21 to CDK2 and a subsequent arrest of the cells in G1. Whether this entails an active shuttling process or a signaling event leading to nuclear stabilization of p21 was, however, not elucidated. Nonetheless, such a mechanism not only adds to our understanding of how p53 integrates cell cycle arrest and DNA repair in response to DNA damage, but also sheds some light on how p53R2 might influence p53mediated life and death decisions.

In addition to its crucial role in nuclear DNA repair, it appears that the ribonucleotide reductase activity of p53R2 might also be involved in the synthesis of mitochondrial DNA (mtDNA). It was found that inactivating mutations in the RRM2B gene (encoding p53R2) are most likely the cause for the mitochondrial DNA depletion syndrome (MDS). ${ }^{133}$ Furthermore, p53 protein itself stabilizes the mitochondrial genomic integrity also by physically interacting with mtDNA and the mtDNA polymerase $\gamma$ (pol $\gamma)$ thereby enhancing its DNA replication function. ${ }^{134}$ Thus, although p53 induces 
expression of genes involved in the destruction of mitochondria such as Bax and Puma, with the induction of p53R2 and association with pol $\gamma$ it also contributes essentially to their maintenance.

G2 and $\mathbf{S}$ phase-expressed-1. Using a differential subtractive hybridization approach, the $\mathrm{G} 2$ and $\mathrm{S}$ phaseexpressed-1 (GTSE-1) gene, previously named B99, was found to contain a p53-binding site in the promoter region resulting in its transcriptional activation by $p 53 .{ }^{39}$ GTSE-1 is a cell cycle-regulated gene and its induction in response to several DNA damaging agents resulted in an increased fraction of cells displaying a 4N DNA contents and a delay of the G2/M transition. More importantly, the C-terminal region of GTSE-1 was found to physically interact with the C-terminal regulatory domain of p53 causing a negative regulation of p53's transactivation function, protein levels, and p53-dependent apoptosis. ${ }^{135}$ Accordingly, GTSE-1 knock-down resulted in a S/G2-specific increase of p53 protein levels as well as sensitization of the cells to DNA damage-induced apoptosis particularly during these phases of the cell cycle. Owing to the presence of an active nuclear export signal (NES), GTSE-1 is able to promote the cytoplasmic localization of p53 causing indirectly its transcriptional suppression. Both GTSE-1-mediated mechanisms of p53 inactivation, nucleo-cytoplasmic shuttling and reduction of its protein stability, appear to require a functional MDM2 protein. ${ }^{136}$ Thus, GTSE-1 may play an important role in DNA damage responses, probably by preventing prolonged p53 activation.

Hematopoietic zinc finger. Over the past few years several p53-interacting proteins were identified that were shown to modulate the transcriptional activity of $p 53 .^{10,123}$ Except for a postulated p53-mediated repression of the pro-apoptotic p53-binding protein-2 (53BP2), expression of these proteins is currently assumed not to be regulated by $\mathrm{p} 53$. In contrast, the hematopoietic zinc finger protein $(\mathrm{Hzf})$ was reported to be a direct target of p53 in NIH-3T3 cells that contributes to the maintenance of the G2 checkpoint and survival upon induction by DNA damage. ${ }^{40}$ Eliminating Hzf expression abrogated the G2 arrest and sensitized cells to DNA damage-induced apoptosis. Interestingly, this effect was accompanied by increased polyubiquitination and turnover of p21, an event that was only explained very recently. ${ }^{137}$ Here the authors confirmed that also human Hzf is under the control of p53 and modulates p53 transactivation functions in an autoregulatory feedback loop. This pathway was uncovered by the observation that in the presence of $\mathrm{Hzf}$ p53 predominantly binds to promoters of pro-arrest targets such as p21 and 14-3-3 $\delta$, whereas this association significantly decreased in Hzf-deficient cells with a concomitant enhancement of p53 bound to promoters of pro-apoptotic genes. Consistently, etoposide-treated Hzfdeficient cells expressed considerably lower amounts of p21 than their similar treated wild-type counterparts, whereas Bax levels in these cells correlated negatively with the Hzf status. Thus, Hzf selectively directs p53 toward induction of cell cycle arrest genes mediating pro-survival signals and actively neglecting transcription of pro-apoptotic genes.
Similar observations were also obtained in vivo as several tissues from $H z f$-null mice exposed to total body $\gamma$-irradiation displayed increased cell death when compared with wild-type littermates and protection from apoptosis correlated positively with $\mathrm{Hzf}$ expression. ${ }^{137}$ Interestingly, the authors also found that the level of Hzf protein correlated inversely with the extent of a genotoxic stress signal as Hzf undergoes extensive ubiquitination and proteasomal degradation following prolonged stress exposure resulting in induction of pro-apoptotic genes. Together, these data provide an attractive explanation for the observation that extended damage triggers a switch from a growth-inhibitory transcriptional program to a pro-apoptotic one. It will be now of particular interest to study the role of Hzf in cancer and whether alterations in its expression are involved in tumorigenesis particularly in those tumors that retain a functional wild-type p53 protein.

\section{p53 and Mitogen-Activated Protein Kinases}

Besides p53 (and of course a multitude of other signaling components), cellular stress induces also activation of the mitogen-activated protein kinase (MAPK) family whose members are involved in diverse cellular responses such as growth, differentiation and apoptosis. ${ }^{84}$ Although MAPKs influence apoptotic signaling pathways by several means in either direction, SAPK/JNK and p38 are believed to be mainly involved in pro-apoptotic signaling, whereas ERK can be considered as part of a pro-survival pathway that counteracts the pro-apoptotic $\mathrm{BH} 3$-only protein Bim. ${ }^{138}$

Heparin-binding epidermal growth factor-like growth factor. Using expression array analysis, the heparinbinding epidermal growth factor-like growth factor (HBEGF) was identified as a novel p53 target that mediates ras/raf-dependent ERK activation through binding to the EGF receptor (EGFR) (Figure 4). ${ }^{42}$ Consistent with the tremendous pro-survival signaling capabilities of the EGF receptor that is also a transcriptional target of $\mathrm{p} 53,{ }^{41}$ overexpression of HB-EGF was shown to confer resistance to apoptosis induced by oxidative stress $^{42}$ and chemotherapeutic agents, ${ }^{139}$ and was even found to protect mice from lethal CD95-induced liver injury. ${ }^{140}$ In addition to the activation of ERK, HB-EGF-mediated EGFR signaling also resulted in the activation of the phosphatidylinositol-3-kinase (PI3K)/Akt pathway, ${ }^{42}$ a major cell survival pathway often activated in cancer cells. Akt exerts its various anti-apoptotic effects not only downstream of $\mathrm{p} 53$ by phosphorylating and thereby inhibiting proapoptotic proteins such as Bad, caspase- 9 and ASK1, but also by destabilizing p53 through phosphorylation of MDM2 at Ser166 and Ser186 which was shown to be required for the shuttling of MDM2 into the nucleus. ${ }^{141}$

Discoidin domain receptor 1 . In an identical experimental setup, the discoidin domain receptor 1 (DDR1) gene encoding a receptor tyrosine kinase was also identified as a p53-regulated gene that is induced in response to genotoxic stressors due to a p53 response element within intron $3 .{ }^{43}$ Overexpression of DDR1-reduced p53-dependent 
apoptosis, whereas inhibition of its activity for example by introduction of a dominant-negative (DN) DDR1 construct accelerated IR-induced cell death. The mechanisms by which DDR1 protects cells from apoptosis appear to involve multiple pathways including MAPK, Akt, Bcl- $x_{L}$ and $N F-\kappa B$ (Figure 4). For instance, inhibition of either the MAPK or Akt pathway by U0126 and LY294002, respectively, increased the level of IR-induced apoptosis significantly, whereas expression of a constitutive active Raf mutant that acts downstream of DDR1, but upstream of MAPKcounteracted DN-DDR1-mediated cell death. Interestingly, although p53-induced expression of DDR1 resulted in an ARF-dependent upregulation of p53 thereby enforcing a positive feedback loop, the increased p53 activity was only associated with elevated $\mathrm{Bcl}-\mathrm{x}_{\mathrm{L}}, \mathrm{p} 21$ and MDM2 levels. Expression of pro-apoptotic p53 targets such as Noxa and Puma in contrast was not affected. Thus, it appears that the enhanced phosphorylation of p53 at serine 15 that was also observed upon DDR1 induction regulates p53's transcriptional activity preferentially toward induction of antiapoptotic genes. DDR1 was also found to inhibit CD95mediated apoptosis and to induce activation of NF- $\kappa \mathrm{B},{ }^{142,143}$ an observation that might help to explain upregulation of $\mathrm{BCl}-\mathrm{xL}$ in stressed cells. Exactly how p53 induces phosphorylation-dependent activation of DDR1 is unknown as it was achieved independently of its natural ligand collagen indicating that p53 mediates DDR1 activation either via yet unknown ligands, or by a ligand-independent mechanism that remains to be resolved.

Nonetheless, studies in knockout mice confirmed a role for DDR1 in cellular proliferation, attachment and migration; however, analyses into cellular responses to DNA stresses of these mice were unfortunately not undertaken. ${ }^{144}$ It appears though that this tyrosine kinase receptor may play a role in the progression of certain malignancies as DDR1 was found overexpressed in various carcinomas ${ }^{145}$ and high DDR1 expression correlated negatively with survival in several malignant glioma patients. ${ }^{146}$

Cyclooxygenase 2. Finally, either dependent on the HBEGF-induced activation of the ras/raf/MAPK pathway or in cooperation with NF- $\kappa \mathrm{B}, \mathrm{p} 53$ induces expression of the cyclooxygenase 2 (Cox-2) gene following exposure to various DNA-damaging agents. ${ }^{44,147}$ Cox-2, a crucial enzyme in prostaglandin synthesis is often overexpressed in many solid tumors and associated with tumor aggressiveness due to its well documented anti-apoptotic and tumor-promoting capabilities. ${ }^{148,149}$ Cox-2 was also demonstrated to regulate p53-induced apoptosis, as the rate of cell death following DNA damage was potentiated not only in Cox-2-deficient cells, but also in cells in which Cox-2 activity was suppressed by non-steroidal anti-inflammatory drugs such as NS-398 and celecoxib. Several mechanisms were postulated to contribute to the anti-apoptotic effect of Cox-2 including the metabolism of its pro-apoptotic substrate arachidonic acid and subsequent synthesis of the survival factor prostaglandin, as well as augmenting expression and activity of Bcl-2 and Akt (Figure 4). ${ }^{148}$ In addition, Cox-2 appears to directly modulate p53 activity at several levels as firstly, overexpression of Cox-2 was found to promote the binding of $\mathrm{p} 53$ to MDM2 resulting in a diminished nuclear accumulation of p53 protein. Consistent with this, Cox-2 inhibitors enhanced chemosensitivity by downregulating HDM2 thereby augmenting p53 stability. ${ }^{150}$ Secondly, Cox-2 was shown to physically interact with p53 both in vitro and in vivo suppressing not only basal, but also activation-induced transcriptional activity of p53, an effect that was mimicked by the addition of prostaglandin and abrogated by NS-398. ${ }^{150}$ Such a negative feedback mechanism might be especially important during inflammatory responses that also result in DNA damage and that require the pro-apoptotic capabilities of p53 to be kept tightly in check. ${ }^{148}$

Although it remains to be elucidated whether p53 induces HB-EGF expression (and subsequently Akt and Cox-2 activation) in a direct or indirect manner, with the induction of this and the DDR1 pathway, p53 entails powerful antiapoptotic mechanisms that appear to be crucial determinants for the maintenance of the delicate balance between life and death in response to DNA damage. In addition, these pathways may not only affect the cells directly subjected to genotoxic stress, but also neighboring cells due to the anticipated paracrine role of a growth factor such as HB-EGF.

Wild-type p53-induced phosphatase 1. MAPK are activated through the reversible phosphorylation by socalled MAPK kinases, whereas several phosphatases counteract this process. As MAPKs phosphorylate p53 at multiple sites thereby modulating its stabilization and activation, ${ }^{84}$ it was interesting to learn that p53 in turn also suppresses this pathway by directly inducing expression of phosphatases known to negatively regulate MAPK signaling.

The oncogenic serine/threonine phosphatase Wip1 (wildtype p53-induced protein-1) encoded by the protein phosphatase magnesium-dependent-1 delta gene was shown to be upregulated in a p53-dependent manner by a variety of DNA damaging agents. ${ }^{45,151}$ The first identified target protein of Wip1 was the p38 MAP kinase and Wip1-mediated dephosphorylation of p38 at Thr180 strongly suppressed its kinase activity. ${ }^{151}$ Because $\mathrm{p} 38$ activates $\mathrm{p} 53$ by phosphorylating it at multiple sites crucial for apoptosis signaling, the inactivation of p38 represents a negative feedback regulatory loop by which Wip1 indirectly suppresses p53's pro-apoptotic function. In addition, WIP1-mediated inhibition of p38 kinase activity was also implicated to affect the oncogene-induced p19ARFMDM2-p53 pathway in which p19ARF serves as an activator of p53 by sequestering MDM2. Accordingly, inactivation of Wip1 resulted in an increased p38 MAP kinase-mediated expression of p19ARF thereby causing increased p53 activity. $^{152}$ Interestingly, there appears to exist an inverse correlation between p14ARF expression and p53 function in human tumor cell lines consistent with the finding that p53 negatively regulates $\mathrm{p} 14 \mathrm{ARF}$ expression. ${ }^{153}$

Besides the inactivation of p38, Wip1 was recently shown to directly target and inhibit also other crucial components in the DNA damage-induced p53 activation pathway including p53 itself. ${ }^{154-156}$ Wip1 dephosphorylates the PI3 kinase ATM in vivo and in vitro at Ser1981, ${ }^{154}$ a site critical for ATM monomerization and activation. Accordingly, deficiency of Wip1 resulted in activation of ATM, while its overexpression 
was sufficient to reduce activation of the ATM-dependent signaling cascade including p53 activation after DNA damage. In addition, three direct ATM/ATR targets, Chk1, MDM2 and p53, were found to be directly dephosphorylated by Wip1 at Ser345, Ser395 and Ser15, respectively in vitro and in vivo resulting in a reduced p53 phosphorylation at Ser20, and, in addition, in its MDM2-mediated degradation. ${ }^{155,156}$ Thus, the direct and indirect dephosphorylation of p53 at Ser15 and Ser20 interferes not only with the MDM2-mediated inactivation of p53, but also hampers p53's apoptotic function as phosphorylation at Ser15 was shown to be critical in this process. Consistent with the role of p53 in cell cycle control, Wip1-mediated dephosphorylation of p53 correlated with reduced cellular intra-S and G2/M checkpoint activity in response to DNA damage. By abrogating cell cycle checkpoints, Wip1 overexpression would likely result in increased proliferation and chromosomal instability as this phosphatase was also found to inhibit base excision repair. ${ }^{157}$ Indeed, Wip1 positively regulates cellular proliferation and complements several oncogenes for cell transformation and thus behaves as an oncogene. In addition, Wip1 is amplified and overexpressed in a subset of human breast cancers, neuroblastomas and adenocarcinomas that invariably retain wild-type p53 alleles. Importantly, virtually none of the breast cancers with Wip1 amplification exhibited p53 mutations ${ }^{158}$ indicating that overexpression of Wip1 is a powerful way to inactivate the pro-apoptotic p53 signaling pathways.

Together, it appears that Wip1 is able to suppress p53 activity by at least five direct or indirect mechanisms: (1) direct dephosphorylation of Ser15 of p53; (2) reduced phosphorylation of Ser20 of p53 through dephosphorylation of Chk1; (3) reduced phosphorylation of Ser33 and Ser46 of p53 through dephosphorylation and inactivation of p38 MAP kinase; (4) increased MDM2 interaction with p53 and its subsequent degradation through suppression of $p 19 A R F$ via reduced $p 38$ activity; (5) increased degradation of $\mathrm{p} 53$ by stabilizing MDM2 (Figure 4).

\section{Mitogen-activated protein kinase phosphatase-1. Also} MKP1, the founding member of the dual-specificity protein phosphatase family, was found to be a direct transcriptional target of $553 .{ }^{46}$ Functional studies revealed a marked influence of this phosphatase on p53-mediated cell cycle arrest. Whereas inhibition of its phosphatase activity by vanadate impaired p53-mediated G1-arrest in human glioblastoma cells in response to growth factor stimuli, conditional expression of MKP1 prevented arrested human lung cancer cells from entering into the cell cycle. More importantly, MKP1 inhibited apoptosis induced by UV ${ }^{159}$ and cisplatin. ${ }^{160}$ Although MKP1 was originally identified as an ERK-specific phosphatase, it is now known to also inhibit JNK and p38 that are both involved in stabilization and activation of $p 53$ through multiple phosphorylation events. ${ }^{84}$

Interestingly, p53 positively regulates also two other dualspecificity phosphatases, PAC1 and DUSP5, that are both capable of inactivating all three major MAPK signaling pathways ${ }^{161,162}$ and hence might act in a similar manner to Wip1 and MKP1 in suppressing apoptosis via indirect inactivation of p53. However, whereas the role of DUSP5 in p53-mediated apoptosis pathways has not been evaluated yet, modulation of PAC1 expression was clearly shown to exert the opposite effect as it participates in sensitizing cells to apoptosis induced by serum starvation and $\mathrm{H}_{2} \mathrm{O}_{2}$ treatment.

\section{And Even More Anti-Apoptotic p53 Targets}

In addition to the above-mentioned anti-apoptotic proteins, p53 also regulates expression of several other proteins known to counteract apoptosis signaling (Table 1). These include the checkpoint kinase- $2,{ }^{47}$ the two TRAIL decoy receptors DcR1 and DcR2 $2^{48,49}$ as well as netrin- $1^{50}$ that inhibits apoptosis signaling mediated by dependence receptors. However, due to strict space constraints, it was impossible to include them into the present review, but the relevant information is provided in the Supplementary Information file.

\section{Conclusion}

There is little doubt that the intriguing armada of anti-apoptotic components p53 has at its disposal, and especially those involved in DNA repair, cell cycle control and the maintenance of the cellular redox state are of utmost importance for the development of a healthy organism. ${ }^{163}$ Why then cannot tumors stand $\mathrm{p} 53^{164}$ and select against such powerful prosurvival mechanisms that clearly would be tremendously advantageous for them? Firstly, tumor cells do not select against those mechanisms, but against the powerful tumor suppressor functions of p53 that make cancer development in its presence a rather unlikely event. In addition, many of the p53-induced proteins discussed here not only protect cells from DNA damage-induced apoptosis (clearly favoring tumorigenesis), but due to their functions for instance in DNA repair or oxidative stress responses also prevent genomic instability and cancer development and thus, still act in a tumor suppressive manner. Secondly, not all tumors might waste these functions, as several cancers that have escaped p53 surveillance show enhanced expression of p53regulated anti-apoptotic proteins that might have more or less contributed to tumorigenesis. ${ }^{165}$ Thirdly, mutations of p53 do not always necessarily imply its non-functionality. In fact, many research groups have identified p53 mutant proteins with a 'gain-of-function' phenotype that rendered these cells resistant to chemotherapy compared to cells that lack p53. ${ }^{166,167}$ Thus, such findings indicate that mutant p53 proteins must have acquired mechanisms allowing them perhaps to selectively induce expression of anti-apoptotic genes while transcription of pro-apoptotic genes might be blocked. ${ }^{168}$ A selection for such a mutant p53 protein would then be surely beneficial for tumor development. Alternatively, mutant p53 might physically interact and inhibit other proapoptotic proteins as previously demonstrated for p63 and p73. ${ }^{169,170}$ Likewise, whereas transcription of the pro-survival insulin growth factor-1 receptor gene is repressed by wild-type p53, it is apparently activated by a mutant p53 protein. ${ }^{171}$ Nevertheless, although the numerous pro-apoptotic activities of p53 are kept tightly in check by almost a similar number of directly acting counter measures or negative feedback mechanisms that can pitch in upon different stress conditions, with the inactivation of the p53 pathway it appears that many tumors rather act on the principle 'better save than sorry'. 
Although we have really learnt a lot about p53 in the past two decades (more than 43000 publications on p53), we are still far from understanding the mechanisms governing its versatile functions. Clearly, several co-factors can selectively modulate p53 transcription and these factors are most likely set in place by a multitude of conditions including cellular context as well as type, strength and duration of a stimulus that are known to critically determine the fate of a cell. ${ }^{10,123}$ However, exactly how these conditions impose on p53 and stimulate partially opposing pathways is mostly beyond our knowledge. Trying to accommodate as much of the overwhelming information as possible, several models were suggested to explain the trouble we have with the decisionmaking process of p53. Assuming for example that p53 itself plays no role in determining the cellular stress response, a 'dumb' p53 might always send the same signals after activation, including induction of pro- and anti-apoptotic genes. ${ }^{172}$ In this case, the outcome of a p53 activation might depend on the availability of the afore mentioned cofactors regulating even a tissue-specific expression of genes, ${ }^{123}$ as it was observed for instance with Slug and 14-3-3 that are predominantly expressed in hematopoietic progenitor and epithelial cells, respectively. Also different promoter strengths of pro- versus anti-apoptotic genes might then be crucial; however, no definite correlation between promoter binding and apoptosis induction has yet been established. ${ }^{173}$ Furthermore, such a behavior can also count towards activities of a 'smart' p53 that might govern, at least in part, its own activities. ${ }^{172}$ Such 'smart' activities might then be further supported for example by multiple post-translational modifications that act upon p53 in an as yet not clearly elucidated manner. Despite the difficulties we have in explaining the mechanisms that decide between life and death, it is unquestionable that p53 actively contributes to both pathways. Although the two opposing functions of p53 seem to annihilate each other, they are definitely not mutually exclusive and provide p53 with an exceptionally powerful tool to fine tune its own activities. Such a tool is especially desirable in stress responses that occur for example during normal physiological processes such as respiration and replication or during immunoglobulin heavy chain class-switch recombination. As all these events are associated with DNA double-strand breaks to which activated p53 is recruited, mechanisms must exist that under these conditions prevent or counteract the pro-apoptotic functions that might be simultaneously induced by 'dumb' p53. And which other molecule would be better predestined to take on such a crucial task either alone or in a concerted action with other factors than 'smart' p53 itself.

Acknowledgements. We are grateful for the critical comments and suggestions by Drs. Frank Essmann (University of Düsseldorf) and Bernd Kaina (University of Mainz) and would like to sincerely apologize to all the colleagues whose excellent work could not be cited here due to space constraints. This work was supported by grants from the Deutsche Forschungsgemeinschaft (SFB 728, TP B1) and the Deutsche Krebshilfe.

1. Oren M. Decision making by p53: life, death and cancer. Cell Death Differ 2003; 10 : 431-442.
2. Yee KS, Vousden KH. Complicating the complexity of p53. Carcinogenesis 2005; 26: $1317-1322$

3. Olsson A, Manzl C, Strasser A, Villunger A. How important are post-translational modifications in p53 for selectivity in target-gene transcription and tumour suppression? Cell Death Differ 2007; 14: 1561-1575.

4. Rozan LM, El-Deiry WS. p53 downstream target genes and tumor suppression: a classical view in evolution. Cell Death Differ 2007; 14: 3-9.

5. Michalak E, Villunger A, Erlacher M, Strasser A. Death squads enlisted by the tumour suppressor p53. Biochem Biophys Res Commun 2005; 331: 786-798.

6. Chipuk JE, Green DR. Dissecting p53-dependent apoptosis. Cell Death Differ 2006; 13: 994-1002.

7. Chen L, Willis SN, Wei A, Smith BJ, Fletcher JI, Hinds MG et al. Differential targeting of prosurvival $\mathrm{Bcl}-2$ proteins by their $\mathrm{BH} 3-$ only ligands allows complementary apoptotic function. Mol Cell 2005; 17: 393-403.

8. Tomita Y, Marchenko N, Erster S, Nemajerova A, Dehner A, Klein C et al. WT p53, but not tumor-derived mutants, bind to $\mathrm{Bcl} 2$ via the DNA binding domain and induce mitochondrial permeabilization. J Biol Chem 2006; 281: 8600-8606.

9. Essmann F, Pohlmann S, Gillissen B, Daniel PT, Schulze-Osthoff K, Jänicke RU. Irradiation-induced translocation of p53 to mitochondria in the absence of apoptosis. J Biol Chem 2005; 280: 37169-37177.

10. Vousden KH. Outcomes of p53 activation - spoilt for choice. J Cell Sci 2006; 119: 5015-5020.

11. Chen J, Sadowski I. Identification of the mismatch repair genes PMS2 and MLH1 as p53 target genes by using serial analysis of binding elements. Proc Natl Acad Sci USA 2005; 102: $4813-4818$.

12. Warnick CT, Dabbas B, Ford CD, Strait KA. Identification of a p53 response element in the promoter region of the hMSH2 gene required for expression in A2780 ovarian cancer cells. J Biol Chem 2001; 276: 27363-27370.

13. Hwang BJ, Ford JM, Hanawalt PC, Chu G. Expression of the p48 xeroderma pigmentosum gene is p53-dependent and is involved in global genomic repair. Proc Natl Acad Sci USA 1999; 96: 424-428.

14. Adimoolam S, Ford JM. p53 and DNA damage-inducible expression of the xeroderma pigmentosum group C gene. Proc Natl Acad Sci USA 2002; 99: 12985-12990.

15. Achanta G, Huang P. Role of p53 in sensing oxidative DNA damage in response to reactive oxygen species-generating agents. Cancer Res 2004; 64: 6233-6239.

16. Zhou J, Ahn J, Wilson SH, Prives C. A role for p53 in base excision repair. EMBO J 2001; 20: 914-923.

17. Seo YR, Fishel ML, Amundson S, Kelley MR, Smith ML. Implication of p53 in base excision DNA repair: in vivo evidence. Oncogene 2002; 21: 731-737.

18. el-Deiry WS, Tokino T, Velculescu VE, Levy DB, Parsons R, Trent JM et al. WAF1, a potential mediator of p53 tumor suppression. Cell 1993; 75: 817-825.

19. Hermeking $\mathrm{H}$, Lengauer $\mathrm{C}$, Polyak K, He TC, Zhang L, Thiagalingam S et al. 14-3-3 sigma is a p53-regulated inhibitor of G2/M progression. Mol Cell 1997; 1: 3-11.

20. Shimizu-Yoshida Y, Sugiyama K, Rogounovitch T, Ohtsuru A, Namba H, Saenko V et al. Radiation-inducible hSNK gene is transcriptionally regulated by p53 binding homology element in human thyroid cells. Biochem Biophys Res Commun 2001; 289: 491-498.

21. Burns TF, Fei P, Scata KA, Dicker DT, El-Deiry WS. Silencing of the novel p53 target gene Snk/Plk2 leads to mitotic catastrophe in paclitaxel (taxol)-exposed cells. Mol Cell Biol 2003; 23: 5556-5571.

22. Rouault JP, Falette N, Guehenneux F, Guillot C, Rimokh R, Wang Q et al. Identification of BTG2, an antiproliferative p53-dependent component of the DNA damage cellular response pathway. Nat Genet 1996; 14: 482-486.

23. Ou YH, Chung PH, Hsu FF, Sun TP, Chang WY, Shieh SY. The candidate tumor suppressor BTG3 is a transcriptional target of $\mathrm{p} 53$ that inhibits E2F1. EMBO J 2007; 26: 3968-3980.

24. Yoon KA, Nakamura $Y$, Arakawa $H$. Identification of ALDH4 as a p53-inducible gene and its protective role in cellular stresses. J Hum Genet 2004; 49: 134-140.

25. Hussain SP, Amstad P, He P, Robles A, Lupold S, Kaneko I et al. p53-induced upregulation of MnSOD and GPx but not catalase increases oxidative stress and apoptosis. Cancer Res 2004; 64: 2350-2356.

26. Tan M, Li S, Swaroop M, Guan K, Oberley LW, Sun Y. Transcriptional activation of the human glutathione peroxidase promoter by p53. J Biol Chem 1999; 274: 12061-12066.

27. Velasco-Miguel S, Buckbinder L, Jean P, Gelbert L, Talbott R, Laidlaw J et al. PA26, a novel target of the p53 tumor suppressor and member of the GADD family of DNA damage and growth arrest inducible genes. Oncogene 1999; 18: 127-137.

28. Budanov AV, Shoshani T, Faerman A, Zelin E, Kamer I, Kalinski H et al. Identification of a novel stress-responsive gene Hi95 involved in regulation of cell viability. Oncogene 2002; 21: $6017-6031$

29. Bensaad K, Tsuruta A, Selak MA, Vidal MN, Nakano K, Bartrons $R$ et al. TIGAR, a p53inducible regulator of glycolysis and apoptosis. Cell 2006; 126: 107-120.

30. Wu WS, Heinrichs S, Xu D, Garrison SP, Zambetti GP, Adams JM et al. Slug antagonizes p53-mediated apoptosis of hematopoietic progenitors by repressing puma. Cell 2005; 123: $641-653$.

31. Scholl FA, McLoughlin P, Ehler E, de Giovanni C, Schafer BW. DRAL is a p53-responsive gene whose four and a half LIM domain protein product induces apoptosis. $J$ Cell Biol 2000; 151: 495-506. 
32. Lin $\mathrm{Y}, \mathrm{Ma} \mathrm{W}$, Benchimol S. Pidd, a new death-domain-containing protein, is induced by p53 and promotes apoptosis. Nat Genet 2000; 26: 122-127.

33. Kartasheva NN, Contente A, Lenz-Stoppler C, Roth J, Dobbelstein M. p53 induces the expression of its antagonist p73 Delta N, establishing an autoregulatory feedback loop. Oncogene 2002; 21: 4715-4727.

34. Zhang W, Geiman DE, Shields JM, Dang DT, Mahatan CS, Kaestner KH et al. The gutenriched Kruppel-like factor (Kruppel-like factor 4) mediates the transactivating effect of p53 on the p21WAF1/Cip1 promoter. J Biol Chem 2000; 275: 18391-18398.

35. Barak $Y$, Juven T, Haffner R, Oren M. mdm2 expression is induced by wild type p53 activity. EMBO J 1993; 12: 461-468.

36. Dornan D, Wertz I, Shimizu H, Arnott D, Frantz GD, Dowd P et al. The ubiquitin ligase COP1 is a critical negative regulator of p53. Nature 2004; 429: 86-92.

37. Leng RP, Lin Y, Ma W, Wu H, Lemmers B, Chung S et al. Pirh2, a p53-induced ubiquitinprotein ligase, promotes p53 degradation. Cell 2003; 112: 779-791.

38. Tanaka H, Arakawa H, Yamaguchi T, Shiraishi K, Fukuda S, Matsui K et al. A ribonucleotide reductase gene involved in a p53-dependent cell-cycle checkpoint for DNA damage. Nature 2000; 404: 42-49.

39. Utrera R, Collavin L, Lazarevic D, Delia D, Schneider C. A novel p53-inducible gene coding for a microtubule-localized protein with G2-phase-specific expression. EMBO J 1998; 17: 5015-5025.

40. Sugimoto M, Gromley A, Sherr CJ. Hzf, a p53-responsive gene, regulates maintenance of the G2 phase checkpoint induced by DNA damage. Mol Cell Biol 2006; 26: 502-512.

41. Deb SP, Munoz RM, Brown DR, Subler MA, Deb S. Wild-type human p53 activates the human epidermal growth factor receptor promoter. Oncogene 1994; 9: 1341-1349.

42. Fang L, Li G, Liu G, Lee SW, Aaronson SA. p53 induction of heparin-binding EGF-like growth factor counteracts $\mathrm{p} 53$ growth suppression through activation of MAPK and PI3K/ Akt signaling cascades. EMBO J 2001; 20: 1931-1939.

43. Ongusaha PP, Kim JI, Fang L, Wong TW, Yancopoulos GD, Aaronson SA et al. p53 induction and activation of DDR1 kinase counteract p53-mediated apoptosis and influence p53 regulation through a positive feedback loop. EMBO J 2003; 22: 1289-1301.

44. Han JA, Kim JI, Ongusaha PP, Hwang DH, Ballou LR, Mahale A et al. P53-mediated induction of Cox-2 counteracts p53- or genotoxic stress-induced apoptosis. EMBO J 2002; 21: 5635-5644.

45. Fiscella M, Zhang H, Fan S, Sakaguchi K, Shen S, Mercer WE et al. Wip1, a novel human protein phosphatase that is induced in response to ionizing radiation in a p53-dependent manner. Proc Natl Acad Sci USA 1997; 94: 6048-6053.

46. Li M, Zhou JY, Ge Y, Matherly LH, Wu GS. The phosphatase MKP1 is a transcriptional target of p53 involved in cell cycle regulation. J Biol Chem 2003; 278: 41059-41068.

47. Matsui $T$, Katsuno $Y$, Inoue $T$, Fujita $F$, Joh $T$, Niida $H$ et al. Negative regulation of Chk2 expression by $\mathrm{p} 53$ is dependent on the CCAAT-binding transcription factor NF-Y. J Biol Chem 2004; 279: 25093-25100.

48. Ruiz de Almodovar C, Ruiz-Ruiz C, Rodriguez A, Ortiz-Ferron G, Redondo JM, LopezRivas A. Tumor necrosis factor-related apoptosis-inducing ligand (TRAIL) decoy receptor TRAIL-R3 is up-regulated by p53 in breast tumor cells through a mechanism involving an intronic p53-binding site. J Biol Chem 2004; 279: 4093-4101.

49. Liu X, Yue P, Khuri FR, Sun SY. Decoy receptor 2 (DcR2) is a p53 target gene and regulates chemosensitivity. Cancer Res 2005; 65: 9169-9175.

50. Arakawa H. Netrin-1 and its receptors in tumorigenesis. Nat Rev Cancer 2004; 4 : 978-987.

51. Roos WP, Kaina B. DNA damage-induced cell death by apoptosis. Trends Mol Med 2006; 12: $440-450$.

52. Sengupta S, Harris CC. p53: traffic cop at the crossroads of DNA repair and recombination. Nat Rev Mol Cell Biol 2005; 6: 44-55.

53. Xanthoudakis S, Smeyne RJ, Wallace JD, Curran T. The redox/DNA repair protein, Ref-1, is essential for early embryonic development in mice. Proc Natl Acad Sci USA 1996; 93: 8919-8923.

54. Sugo N, Aratani $Y$, Nagashima $Y$, Kubota $Y$, Koyama $H$. Neonatal lethality with abnormal neurogenesis in mice deficient in DNA polymerase beta. EMBO J 2000; 19: 1397-1404.

55. Hirano $T$, Kawai K, Ootsuyama $Y$, Orimo $H$, Kasai $H$. Detection of a mouse OGG1 fragment during caspase-dependent apoptosis: oxidative DNA damage and apoptosis. Cancer Sci 2004; 95: 634-638.

56. Gu Y, Jin S, Gao Y, Weaver DT, Alt FW. Ku70-deficient embryonic stem cells have increased ionizing radiosensitivity, defective DNA end-binding activity, and inability to support V(D)J recombination. Proc Natl Acad Sci USA 1997; 94: 8076-8081.

57. Gao Y, Ferguson DO, Xie W, Manis JP, Sekiguchi J, Frank KM et al. Interplay of p53 and DNA-repair protein XRCC4 in tumorigenesis, genomic stability and development. Nature 2000; 404: 897-900.

58. Frank KM, Sharpless NE, Gao Y, Sekiguchi JM, Ferguson DO, Zhu C et al. DNA ligase IV deficiency in mice leads to defective neurogenesis and embryonic lethality via the p53 pathway. Mol Cell 2000; 5: 993-1002.

59. Brown KD, Lataxes TA, Shangary S, Mannino JL, Giardina JF, Chen J et al. lonizing radiation exposure results in up-regulation of Ku70 via a p53/ataxia-telangiectasiamutated protein-dependent mechanism. J Biol Chem 2000; 275: 6651-6656.

60. Cohen HY, Lavu S, Bitterman KJ, Hekking B, Imahiyerobo TA, Miller C et al. Acetylation of the $\mathrm{C}$ terminus of Ku70 by CBP and PCAF controls Bax-mediated apoptosis. Mol Cell 2004; 13: 627-638.
61. Mazumder S, Plesca D, Kinter M, Almasan A. Interaction of a cyclin E fragment with Ku70 regulates Bax-mediated apoptosis. Mol Cell Biol 2007; 27: 3511-3520.

62. Seifert M, Reichrath J. The role of the human DNA mismatch repair gene hMSH2 in DNA repair, cell cycle control and apoptosis: implications for pathogenesis, progression and therapy of cancer. J Mol Histol 2006; 37: 301-307.

63. Prtilo A, Leach FS, Markwalder R, Kappeler A, Burkhard FC, Cecchini MG et al. Tissue microarray analysis of $\mathrm{hMSH} 2$ expression predicts outcome in men with prostate cancer. J Urol 2005; 174: 1814-1818; discussion 1818.

64. Chen F, Arseven OK, Cryns VL. Proteolysis of the mismatch repair protein MLH1 by caspase-3 promotes DNA damage-induced apoptosis. J Biol Chem 2004; 279 : 27542-27548.

65. Smith ML, Seo YR. p53 regulation of DNA excision repair pathways. Mutagenesis 2002; 17: 149-156.

66. Smith ML, Fornace Jr AJ. p53-mediated protective responses to UV irradiation. Proc Natl Acad Sci USA 1997; 94: 12255-12257.

67. Tan T, Chu G. p53 Binds and activates the xeroderma pigmentosum DDB2 gene in humans but not mice. Mol Cell Biol 2002; 22: 3247-3254.

68. Taylor WR, Stark GR. Regulation of the G2/M transition by p53. Oncogene 2001; 20: 1803-1815.

69. Jänicke RU, Sohn D, Essmann F, Schulze-Osthoff K. The multiple battles fought by anti-apoptotic p21. Cell Cycle 2007; 6: 407-413.

70. Hermeking H. The 14-3-3 cancer connection. Nat Rev Cancer 2003; 3: 931-943.

71. Dougherty MK, Morrison DK. Unlocking the code of 14-3-3. J Cell Sci 2004; 117: 1875-1884.

72. Dellambra E, Golisano O, Bondanza S, Siviero E, Lacal P, Molinari M et al. Downregulation of 14-3-3sigma prevents clonal evolution and leads to immortalization of primary human keratinocytes. J Cell Biol 2000; 149: 1117-1130.

73. Tzivion G, Gupta VS, Kaplun L, Balan V. 14-3-3 proteins as potential oncogenes. Semin Cancer Biol 2006; 16: 203-213.

74. Chan TA, Hermeking H, Lengauer C, Kinzler KW, Vogelstein B. 14-3-3Sigma is required to prevent mitotic catastrophe after DNA damage. Nature 1999; 401: 616-620.

75. Chan TA, Hwang PM, Hermeking H, Kinzler KW, Vogelstein B. Cooperative effects of genes controlling the G(2)/M checkpoint. Genes Dev 2000; 14: 1584-1588.

76. Zha J, Harada H, Yang E, Jockel J, Korsmeyer SJ. Serine phosphorylation of death agonist $B A D$ in response to survival factor results in binding to 14-3-3 not $B C L-X(L)$. Cell 1996; 87: 619-628.

77. Ranger AM, Zha J, Harada H, Datta SR, Danial NN, Gilmore AP et al. Bad-deficient mice develop diffuse large B cell lymphoma. Proc Natl Acad Sci USA 2003; 100: 9324-9329.

78. Villunger A, Michalak EM, Coultas L, Mullauer F, Bock G, Ausserlechner MJ et al. p53and drug-induced apoptotic responses mediated by $\mathrm{BH} 3$-only proteins puma and noxa. Science 2003; 302: 1036-1038.

79. Eckerdt F, Yuan J, Strebhardt K. Polo-like kinases and oncogenesis. Oncogene 2005; 24: 267-276.

80. Li J, Tan M, Li L, Pamarthy D, Lawrence TS, Sun Y. SAK, a new polo-like kinase, is transcriptionally repressed by p53 and induces apoptosis upon RNAi silencing. Neoplasia 2005; 7: 312-323.

81. Tirone $F$. The gene PC3(TIS21/BTG2), prototype member of the PC3/BTG/TOB family: regulator in control of cell growth, differentiation, and DNA repair? J Cell Physiol 2001; 187: $155-165$

82. Yoshida Y, Nakamura T, Komoda M, Satoh H, Suzuki T, Tsuzuku JK et al. Mice lacking a transcriptional corepressor Tob are predisposed to cancer. Genes Dev 2003; 17: 1201-1206.

83. Finkel T. Oxidant signals and oxidative stress. Curr Opin Cell Biol 2003; 15: 247-254.

84. Wu GS. The functional interactions between the p53 and MAPK signaling pathways. Cancer Biol Ther 2004; 3: 156-161.

85. Ueda S, Masutani H, Nakamura H, Tanaka T, Ueno M, Yodoi J. Redox control of cell death. Antioxid Redox Signal 2002; 4: 405-414.

86. Yoshida A, Rzhetsky A, Hsu LC, Chang C. Human aldehyde dehydrogenase gene family. Eur J Biochem 1998; 251: 549-557.

87. Donald SP, Sun XY, Hu CA, Yu J, Mei JM, Valle D et al. Proline oxidase, encoded by p53induced gene-6, catalyzes the generation of proline-dependent reactive oxygen species. Cancer Res 2001; 61: 1810-1815.

88. Pani G, Colavitti R, Bedogni B, Fusco S, Ferraro D, Borrello $S$ et al. Mitochondrial superoxide dismutase: a promising target for new anticancer therapies. Curr Med Chem 2004; 11: 1299-1308.

89. Ridnour LA, Oberley TD, Oberley LW. Tumor suppressive effects of MnSOD overexpression may involve imbalance in peroxide generation versus peroxide removal. Antioxid Redox Signal 2004; 6: 501-512.

90. Drane P, Bravard A, Bouvard V, May E. Reciprocal downregulation of p53 and SOD2 gene expression-implication in p53-mediated apoptosis. Oncogene 2001; 20: 430-439.

91. Godwin AK, Meister A, O'Dwyer PJ, Huang CS, Hamilton TC, Anderson ME. High resistance to cisplatin in human ovarian cancer cell lines is associated with marked increase of glutathione synthesis. Proc Natl Acad Sci USA 1992; 89: 3070-3074.

92. Lai GM, Moscow JA, Alvarez MG, Fojo AT, Bates SE. Contribution of glutathione and glutathione-dependent enzymes in the reversal of adriamycin resistance in colon carcinoma cell lines. Int J Cancer 1991; 49: 688-695. 
93. Li S, Yan T, Yang JQ, Oberley TD, Oberley LW. The role of cellular glutathione peroxidase redox regulation in the suppression of tumor cell growth by manganese superoxide dismutase. Cancer Res 2000; 60: 3927-3939.

94. Sun Y, Mu Y, Ma S, Gong P, Yan G, Liu J et al. The molecular mechanism of protecting cells against oxidative stress by 2-selenium-bridged beta-cyclodextrin with glutathione peroxidase activity. Biochim Biophys Acta 2005; 1743: 199-204.

95. Yan W, Chen X. GPX2, a direct target of p63, inhibits oxidative stress-induced apoptosis in a p53-dependent manner. J Biol Chem 2006; 281: 7856-7862.

96. Budanov AV, Sablina AA, Feinstein E, Koonin EV, Chumakov PM. Regeneration of peroxiredoxins by p53-regulated sestrins, homologs of bacterial AhpD. Science 2004; 304: 596-600.

97. Masutani $\mathrm{H}$, Ueda S, Yodoi J. The thioredoxin system in retroviral infection and apoptosis. Cell Death Differ 2005; 12 (Suppl 1): 991-998.

98. Sablina AA, Budanov AV, llyinskaya GV, Agapova LS, Kravchenko JE, Chumakov PM The antioxidant function of the p53 tumor suppressor. Nat Med 2005; 11: 1306-1313.

99. Zhang YM, Liu JK, Wong TY. The DNA excision repair system of the highly radioresistant bacterium Deinococcus radiodurans is facilitated by the pentose phosphate pathway. Mol Microbiol 2003; 48: 1317-1323.

100. Green DR, Chipuk JE. p53 and metabolism: inside the TIGAR. Cell 2006; 126: 30-32.

101. Matoba S, Kang JG, Patino WD, Wragg A, Boehm M, Gavrilova $O$ et al. p53 regulates mitochondrial respiration. Science 2006; 312: 1650-1653.

102. Kondoh H, Lleonart ME, Gil J, Wang J, Degan P, Peters G et al. Glycolytic enzymes can modulate cellular life span. Cancer Res 2005; 65: 177-185.

103. Jones RG, Plas DR, Kubek S, Buzzai M, Mu J, Xu Y et al. AMP-activated protein kinase induces a p53-dependent metabolic checkpoint. Mol Cell 2005; 18: 283-293.

104. Inoue A, Seidel MG, Wu W, Kamizono S, Ferrando AA, Bronson RT et al. Slug, a highly conserved zinc finger transcriptional repressor, protects hematopoietic progenitor cells from radiation-induced apoptosis in vivo. Cancer Cell 2002; 2: 279-288.

105. Haupt S, Alsheich-Bartok O, Haupt Y. Clues from worms: a slug at Puma promotes the survival of blood progenitors. Cell Death Differ 2006; 13: 913-915.

106. Perez-Mancera PA, Gonzalez-Herrero I, Perez-Caro M, Gutierrez-Cianca N, Flores T, Gutierrez-Adan A et al. SLUG in cancer development. Oncogene 2005; 24: 3073-3082.

107. Karin M, Greten FR. NF-kappaB: linking inflammation and immunity to cancer development and progression. Nat Rev Immunol 2005; 5: 749-759.

108. Karin M, Lin A. NF-kappaB at the crossroads of life and death. Nat Immunol 2002; 3 221-227.

109. Janssens S, Tschopp J. Signals from within: the DNA damage-induced NF-kappaB response. Cell Death Differ 2006; 13: 773-784.

110. Perkins ND. Integrating cell-signalling pathways with NF-kappaB and IKK function Nat Rev Mol Cell Biol 2007; 8: 49-62.

111. Tinel A, Tschopp J. The PIDDosome, a protein complex implicated in activation of caspase-2 in response to genotoxic stress. Science 2004; 304: 843-846.

112. Janssens S, Tinel A, Lippens S, Tschopp J. PIDD mediates NF-kappaB activation in response to DNA damage. Cell 2005; 123: 1079-1092.

113. Tinel A, Janssens S, Lippens S, Cuenin S, Logette E, Jaccard B et al. Autoproteolysis of PIDD marks the bifurcation between pro-death caspase-2 and pro-survival NF-kappaB pathway. EMBO J 2007; 26: 197-208.

114. Stilo R, Leonardi A, Formisano L, Di Jeso B, Vito P, Liguoro D. TUCAN/CARDINAL and DRAL participate in a common pathway for modulation of NF-kappaB activation. FEBS Lett 2002; 521: 165-169.

115. Muller M, Schleithoff ES, Stremmel W, Melino G, Krammer PH, Schilling T. One, two, three - p53, p63, p73 and chemosensitivity. Drug Resist Updat 2006; 9: 288-306.

116. Murray-Zmijewski F, Lane DP, Bourdon JC. p53/p63/p73 isoforms: an orchestra of isoforms to harmonise cell differentiation and response to stress. Cell Death Differ 2006; 13: $962-972$.

117. Melino G, Lu X, Gasco M, Crook T, Knight RA. Functional regulation of $p 73$ and p63: development and cancer. Trends Biochem Sci 2003; 28: 663-670.

118. Concin N, Becker K, Slade N, Erster S, Mueller-Holzner E, Ulmer H et al. Transdominant DeltaTAp73 isoforms are frequently upregulated in ovarian cancer. Evidence for their role as epigenetic p53 inhibitors in vivo. Cancer Res 2004; 64: 2449-2460.

119. Pozniak CD, Radinovic S, Yang A, McKeon F, Kaplan DR, Miller FD. An anti-apoptotic role for the p53 family member, p73, during developmental neuron death. Science 2000; 289: 304-306.

120. Rowland BD, Peeper DS. KLF4, p21 and context-dependent opposing forces in cancer Nat Rev Cancer 2006; 6: 11-23.

121. Rowland BD, Bernards R, Peeper DS. The KLF4 tumour suppressor is a transcriptional repressor of p53 that acts as a context-dependent oncogene. Nat Cell Biol 2005; 7 : 1074-1082.

122. Ghaleb AM, Katz JP, Kaestner KH, Du JX, Yang VW. Kruppel-like factor 4 exhibits antiapoptotic activity following gamma-radiation-induced DNA damage. Oncogene 2007; 26: 2365-2373.

123. Braithwaite AW, Del Sal G, Lu X. Some p53-binding proteins that can function as arbiters of life and death. Cell Death Differ 2006; 13: 984-993.

124. Lavin MF, Gueven N. The complexity of p53 stabilization and activation. Cell Death Differ 2006; 13: 941-950

125. Fuchs SY, Adler V, Buschmann T, Yin Z, Wu X, Jones SN et al. JNK targets p53 ubiquitination and degradation in nonstressed cells. Genes Dev 1998; 12: 2658-2663.
126. Dornan D, Shimizu $H$, Mah A, Dudhela $T$, Eby M, O'Rourke $K$ et al. ATM engages autodegradation of the E3 ubiquitin ligase COP1 after DNA damage. Science 2006; 313: 1122-1126.

127. Naik E, Michalak EM, Villunger A, Adams JM, Strasser A. Ultraviolet radiation triggers apoptosis of fibroblasts and skin keratinocytes mainly via the $\mathrm{BH} 3$-only protein Noxa. J Cell Biol 2007; 176: 415-424.

128. Brooks CL, Gu W. p53 ubiquitination: Mdm2 and beyond. Mol Cell 2006; 21: 307-315.

129. Dornan D, Bheddah S, Newton K, Ince W, Frantz GD, Dowd P et al. COP1, the negative regulator of $\mathrm{p53}$, is overexpressed in breast and ovarian adenocarcinomas. Cancer Res 2004; 64: 7226-7230.

130. Logan IR, Gaughan L, McCracken SR, Sapountzi V, Leung HY, Robson CN. Human $\mathrm{PIRH} 2$ enhances androgen receptor signaling through inhibition of histone deacetylase 1 and is overexpressed in prostate cancer. Mol Cell Biol 2006; 26: 6502-6510.

131. Kimura T, Takeda S, Sagiya Y, Gotoh M, Nakamura Y, Arakawa H. Impaired function of p53R2 in Rrm2b-null mice causes severe renal failure through attenuation of dNTP pools. Nat Genet 2003; 34: 440-445.

132. Xue L, Zhou B, Liu X, Heung Y, Chau J, Chu E et al. Ribonucleotide reductase small subunit p53R2 facilitates p21 induction of G1 arrest under UV irradiation. Cancer Res 2007; 67: 16-21.

133. Bourdon A, Minai L, Serre V, Jais JP, Sarzi E, Aubert S et al. Mutation of RRM2B, encoding p53-controlled ribonucleotide reductase (p53R2), causes severe mitochondrial DNA depletion. Nat Genet 2007; 39: 776-780.

134. Achanta G, Sasaki R, Feng L, Carew JS, Lu W, Pelicano H et al. Novel role of p53 in maintaining mitochondrial genetic stability through interaction with DNA Pol gamma. EMBO J 2005; 24: 3482-3492.

135. Monte M, Benetti R, Buscemi G, Sandy P, Del Sal G, Schneider C. The cell cycleregulated protein human GTSE-1 controls DNA damage-induced apoptosis by affecting p53 function. J Biol Chem 2003; 278: 30356-30364.

136. Monte M, Benetti R, Collavin L, Marchionni L, Del Sal G, Schneider C. hGTSE-1 expression stimulates cytoplasmic localization of p53. J Biol Chem 2004; 279: 11744-11752.

137. Das S, Raj L, Zhao B, Kimura Y, Bernstein A, Aaronson SA et al. Hzf Determines cell survival upon genotoxic stress by modulating p53 transactivation. Cell 2007; 130: 624-637.

138. Ewings KE, Hadfield-Moorhouse K, Wiggins CM, Wickenden JA, Balmanno K, Gilley R et al. ERK1/2-dependent phosphorylation of BimEL promotes its rapid dissociation from Mcl-1 and Bcl-xL. EMBO J 2007; 26: 2856-2867.

139. Wang F, Liu R, Lee SW, Sloss CM, Couget J, Cusack JC. Heparin-binding EGF-like growth factor is an early response gene to chemotherapy and contributes to chemotherapy resistance. Oncogene 2007; 26: 2006-2016.

140. Khai NC, Takahashi T, Ushikoshi H, Nagano S, Yuge K, Esaki M et al. In vivo hepatic HBEGF gene transduction inhibits Fas-induced liver injury and induces liver regeneration in mice: a comparative study to HGF. J Hepatol 2006; 44: 1046-1054.

141. Zhou BP, Liao Y, Xia W, Zou Y, Spohn B, Hung MC. HER-2/neu induces p53 ubiquitination via Akt-mediated MDM2 phosphorylation. Nat Cell Biol 2001; 3: 973-982.

142. Matsuyama W, Wang L, Farrar WL, Faure M, Yoshimura T. Activation of discoidin domain receptor 1 isoform $b$ with collagen up-regulates chemokine production in human macrophages: role of p38 mitogen-activated protein kinase and NF-kappa B. J Immunol 2004; 172: 2332-2340.

143. Matsuyama W, Mitsuyama $\mathrm{H}$, Ono M, Shirahama $\mathrm{Y}$, Higashimoto I, Osame $\mathrm{M}$ et al. Discoidin domain receptor 1 contributes to eosinophil survival in an NF-kappaBdependent manner in Churg-Strauss syndrome. Blood 2007; 109: 22-30.

144. Vogel WF, Aszodi A, Alves F, Pawson T. Discoidin domain receptor 1 tyrosine kinase has an essential role in mammary gland development. Mol Cell Biol 2001; 21: 2906-2917.

145. Alves F, Vogel W, Mossie K, Millauer B, Hofler H, Ullrich A. Distinct structural characteristics of discoidin I subfamily receptor tyrosine kinases and complementary expression in human cancer. Oncogene 1995; 10: 609-618.

146. Yamanaka R, Arao T, Yajima N, Tsuchiya N, Homma J, Tanaka R et al. Identification of expressed genes characterizing long-term survival in malignant glioma patients. Oncogene 2006; 25: 5994-6002

147. Benoit V, de Moraes E, Dar NA, Taranchon E, Bours V, Hautefeuille A et al. Transcriptional activation of cyclooxygenase-2 by tumor suppressor $\mathrm{p} 53$ requires nuclear factor-kappaB. Oncogene 2006; 25: 5708-5718.

148. de Moraes E, Dar NA, de Moura Gallo CV, Hainaut P. Cross-talks between cyclooxygenase-2 and tumor suppressor protein p53: balancing life and death during inflammatory stress and carcinogenesis. Int J Cancer 2007; 121: 929-937.

149. Meric JB, Rottey S, Olaussen K, Soria JC, Khayat D, Rixe $O$ et al. Cyclooxygenase-2 as a target for anticancer drug development. Crit Rev Oncol Hematol 2006; 59: 51-64.

150. Lau L, Hansford LM, Cheng LS, Hang M, Baruchel S, Kaplan DR et al. Cyclooxygenase inhibitors modulate the p53/HDM2 pathway and enhance chemotherapy-induced apoptosis in neuroblastoma. Oncogene 2007; 26: 1920-1931.

151. Takekawa M, Adachi M, Nakahata A, Nakayama I, Itoh F, Tsukuda $\mathrm{H}$ et al. p53-inducible wip1 phosphatase mediates a negative feedback regulation of p38 MAPK-p53 signaling in response to UV radiation. EMBO J 2000; 19: 6517-6526

152. Bulavin DV, Phillips C, Nannenga B, Timofeev O, Donehower LA, Anderson CW et al. Inactivation of the Wip1 phosphatase inhibits mammary tumorigenesis through p38 
MAPK-mediated activation of the p16(Ink4a)-p19(Arf) pathway. Nat Genet 2004; 36 343-350.

153. Stott FJ, Bates S, James MC, McConnell BB, Starborg M, Brookes S et al. The alternative product from the human CDKN2A locus, p14(ARF), participates in a regulatory feedback loop with p53 and MDM2. EMBO J 1998; 17: 5001-5014.

154. Shreeram S, Demidov ON, Hee WK, Yamaguchi H, Onishi N, Kek C et al. Wip1 phosphatase modulates ATM-dependent signaling pathways. Mol Cell 2006; 23 757-764.

155. Lu X, Nannenga B, Donehower LA. PPM1D dephosphorylates Chk1 and p53 and abrogates cell cycle checkpoints. Genes Dev 2005; 19: 1162-1174.

156. Lu X, Ma O, Nguyen TA, Jones SN, Oren M, Donehower LA. The Wip1 Phosphatase acts as a gatekeeper in the p53-Mdm2 autoregulatory loop. Cancer Cell 2007; 12: 342-354.

157. Lu X, Bocangel D, Nannenga B, Yamaguchi H, Appella E, Donehower LA. The p53induced oncogenic phosphatase PPM1D interacts with uracil DNA glycosylase and suppresses base excision repair. Mol Cell 2004; 15: 621-634.

158. Bulavin DV, Demidov ON, Saito S, Kauraniemi P, Phillips C, Amundson SA et al. Amplification of PPM1D in human tumors abrogates p53 tumor-suppressor activity. Nat Genet 2002; 31: 210-215.

159. Franklin CC, Srikanth S, Kraft AS. Conditional expression of mitogen-activated protein kinase phosphatase-1, MKP-1, is cytoprotective against UV-induced apoptosis. Proc Natl Acad Sci USA 1998; 95: 3014-3019.

160. Sanchez-Perez I, Martinez-Gomariz M, Williams D, Keyse SM, Perona R. CL100/MKP-1 modulates JNK activation and apoptosis in response to cisplatin. Oncogene 2000; 19: 5142-5152.

161. Yin Y, Liu YX, Jin YJ, Hall EJ, Barrett JC. PAC1 phosphatase is a transcription target of p53 in signalling apoptosis and growth suppression. Nature 2003; 422: 527-531.
162. Camps M, Nichols A, Arkinstall S. Dual specificity phosphatases: a gene family for control of MAP kinase function. FASEB J 2000; 14: 6-16.

163. Vousden KH, Lane DP. p53 in health and disease. Nat Rev Mol Cell Biol 2007; 8 : 275-283.

164. Kastan MB. Wild-type p53: tumors can't stand it. Cell 2007; 128: 837-840.

165. Strano S, Dell'Orso S, Di Agostino S, Fontemaggi G, Sacchi A, Blandino G. Mutant p53: an oncogenic transcription factor. Oncogene 2007; 26: 2212-2219.

166. Blagosklonny MV. p53 from complexity to simplicity: mutant p53 stabilization, gain-offunction, and dominant-negative effect. FASEB J 2000; 14: 1901-1907.

167. Dittmer D, Pati S, Zambetti G, Chu S, Teresky AK, Moore M et al. Gain of function mutations in p53. Nat Genet 1993; 4: 42-46.

168. Weisz L, Oren M, Rotter V. Transcription regulation by mutant p53. Oncogene 2007; 26 : 2202-2211.

169. Strano S, Fontemaggi G, Costanzo A, Rizzo MG, Monti O, Baccarini A et al. Physical interaction with human tumor-derived p53 mutants inhibits p63 activities. J Biol Chem 2002; 277: 18817-18826.

170. Marin MC, Jost CA, Brooks LA, Irwin MS, O'Nions J, Tidy JA et al. A common polymorphism acts as an intragenic modifier of mutant p53 behaviour. Nat Genet 2000; 25: $47-54$.

171. Ohlsson C, Kley N, Werner H, LeRoith D. p53 regulates insulin-like growth factor-I (IGF-I) receptor expression and IGF-I-induced tyrosine phosphorylation in an osteosarcoma cell line: interaction between p53 and Sp1. Endocrinology 1998; 139: 1101-1107.

172. Vousden KH. p53: death star. Cell 2000; 103: 691-694.

173. Kaeser MD, Iggo RD. Chromatin immunoprecipitation analysis fails to support the latency model for regulation of p53 DNA binding activity in vivo. Proc Natl Acad Sci USA 2002; 99 95-100.

Supplementary Information accompanies the paper on Cell Death and Differentiation website (http://www.nature.com/cdd) 